\title{
It is a mess! How many species are in Rivudiva trichobasis Lugo- Ortiz \& McCafferty, 1998 (Ephemeroptera: Baetidae)?
}

\author{
Paulo Vilela CRUZ ${ }^{\circledR 1, *}$, Rafael BOLDRINI ${ }^{\circledR 2}$, \\ Cláudia R.T. DE LIMA ${ }^{\circledR 3}$ \& Neusa HAMADA ${ }^{\circledR 4}$
}

${ }^{1}$ Universidade Federal de Rondônia (UNIR), Programa de Pós-Graduação em Ciências Ambientais,

Programa de Pós-Graduação em Conservação e Uso de Recursos Naturais,

Laboratório de Biodiversidade e Conservação, CEP 76940-000, Rolim de Moura, Rondônia, Brazil.

${ }^{2}$ Universidade Federal de Roraima (UFRR), Campus Paricarana,

Centro de Estudos da Biodiversidade (CBio), CEP 69310-000, Boa Vista, Roraima, Brazil.

1,3,4 Instituto Nacional de Pesquisas da Amazônia (INPA), Coordenação de Pós-Graduação (COPOG),

Divisão do Curso em Entomologia (DiEnt), Coordenação de Biodiversidade (CoBio),

Laboratório de Citotaxonomia e Insetos Aquáticos, CEP 69067-375, Manaus, Amazonas, Brazil.

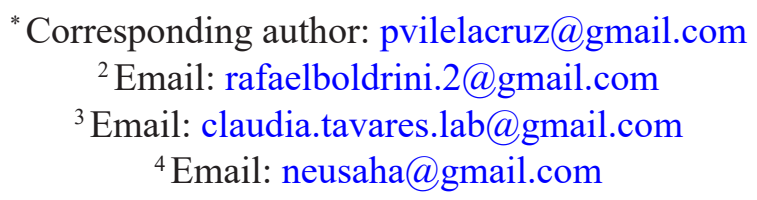

${ }^{1}$ urn:1sid:zoobank.org:author:34F85F41-2743-4248-813F-0CEEE63FE649

${ }^{2}$ urn:lsid:zoobank.org:author:FDC9283D-2B03-4BA9-8631-FB7A57F4D875

${ }^{3}$ urn:1sid:zoobank.org:author:18795D2E-427D-4A26-B112-70C929CA5B95

${ }^{4}$ urn:1sid:zoobank.org:author:0D02F36C-6B09-423C-95A6-6179E9808CD5

\begin{abstract}
The original description of Rivudiva trichobasis Lugo-Ortiz \& McCafferty, 1998 is short, with few illustrations. The lack of information resulted in a broad specific diagnosis, with emphasis on the spine-like setae on the antenna. Our hypothesis is that the lack of information resulted in many species being hidden behind $R$. trichobasis name. We evaluated the species $R$. coveloae (Traver, 1971) and $R$. venezuelensis (Traver, 1943) considering the new evidence. After analyzing the paratype of R. trichobasis and records of the species in Brazil, the hidden-species hypothesis was corroborated. Five new species were identified among the published records of $R$. trichobasis of which four are described here: R. amazona sp. nov. (Roraima State), R. oxum sp. nov. (Rondônia State), R. uiara sp. nov. (Amazonas State), $R$. naia sp. nov. (Roraima State). The fifth species, Rivudiva sp. X from Maranhão State, could not be described due to the poor conservation of the specimen and is therefore left in open nomenclature. Records from Espírito Santo State (Brazil) and from Paraguay are treated as putative and must be evaluated considering the new evidence. Rivudiva venezuelensis and Rivudiva coveloae are diagnosed and illustrated based on type material. After analyzing these two species, we hypothesize that only $R$. coveloae likely belongs to the genus Rivudiva. However, information on the nymphal stage is needed to corroborate this hypothesis.
\end{abstract}

Keywords. Aquatic insect, types, taxonomy, neotropics. 
Cruz P.V., Boldrini R., De Lima C.R.T. \& Hamada N. 2022. It is a mess! How many species are in Rivudiva trichobasis Lugo-Ortiz \& McCafferty, 1998 (Ephemeroptera: Baetidae)? European Journal of Taxonomy 789: 153-191. https://doi.org/10.5852/ejt.2022.789.1639

\section{Introduction}

The genus Rivudiva Lugo-Ortiz \& McCafferty, 1998, although recently established (compared to other genera in the family), already has a rich history. The genus was erected in 1998 to include two species, R. minantenna Lugo-Ortiz \& McCafferty, 1998 (Brazil) and R. trichobasis Lugo-Ortiz \& McCafferty, 1998 (Brazil and Paraguay). Two years later, Orth et al. (2000) reported the genus from French Guyana without specific identification and Salles et al. (2004) reported R. minantenna from Rio de Janeiro State, Brazil, considerably extending its known distributional range.

Domínguez et al. (2006) examined the type material, adding some important characteristics to the original description of both described species. The genus was treated as rare until Salles \& Nascimento (2009), during a mayfly survey in the Southeastern Region of Brazil, found a good series of nymphs of $R$. minantenna and reared a few of them in the field. This study brought to light that species of the genus are psammophilous, allowing subsequent fieldwork sampling to be directed so that a series of discoveries could be made. In the same paper, the authors described the male imago of the genus for the first time (R. minantenna) and, mainly based on a pointed projection on the posterior margin of the subgenital plate, transferred two species only known by their adults to the genus Rivudiva: $R$. coveloae (Traver, 1971) and R. venezuelensis (Traver, 1943).

Cruz et al. (2011) described the male imago of $R$. trichobasis from Amazonas State (Brazil), emending the generic diagnosis and showing that the singular projection on the subgenital plate was absent. Meanwhile, Falcão et al. (2011) reported $R$. trichobasis in Roraima State as well as an atypical species that should be placed in a new genus but that was not described at that time. Soon afterwards, Boldrini et al. (2012) recorded R. trichobasis in northeastern Brazil, and Boldrini \& Cruz (2014) recorded R. trichobasis in Rondônia State (Brazil). Lima et al. (2013) described the same singular projection on the subgenital plate of the adult male of Paracloeodes charrua Emmerich \& Nieto, 2009, stating that it is difficult to ascertain whether this projection represents a convergence or an indication that some species of Rivudiva would be better placed in Paracloeodes Day, 1955. The same doubt was suggested by Gutiérrez et al. (2013) in the case of Varipes singuil Nieto, 2004.

Considering the discussion of supra-specific relationships between genera, Cruz et al. (2018) tested their monophyly using a cladistic approach. As results, Rivudiva, Paracloeodes and Varipes Lugo-Ortiz \& McCafferty, 1998 were delimited, one new genus was erected (Rhopyscelis Cruz, Salles \& Hamada, 2018), and one new genus was flagged, later described as Macuxi Cruz, Salles, Hamada \& Falcão, 2020, with no resolution on species known only by their adults (Cruz et al. 2020).

Two decades of advances in studies of the systematics and taxonomy of the genus has opened the way for further research. The new evidence has allowed understanding why making correct specific assignments was a difficult task. In order to elucidate the identities of old and new specimens, Salles et al. (2020) reevaluated the types and the specimens studied in Salles \& Nascimento (2009), concluding that some of the nymphs of $R$. minantenna collected in Espírito Santo were actually a new species ( $R$. inma Salles \& Nieto in Salles et al., 2020).

The last historical species in the genus to be investigated is $R$. trichobasis, which is the most recorded and has a wide and disjunct distribution. This species is easily distinguishable from others in the genus by 
the presence of spine-like setae on the scape and pedicel. However, excluding the spine-like setae on the antenna, the recently collected specimens could be either R. trichobasis or a new species (PVC pers. obs.).

Two synergistic factors hamper the identification of specimens with spine-like setae on the scape and pedicel. First is the lack of sufficient characteristics and illustrations in the original description; these characteristics are now known to be relevant (as in Apobaetis Day, 1995, see Cruz 2020). The second factor is the paucity of specimens, which makes it difficult to understand the morphological variation and challenges species delimitation, resulting in a broad diagnosis of the species focused on one or a few common characteristics (e.g., spine-like setae of antenna).

Furthermore, based on Rivudiva's biology, suspicions about the identity of records were reinforced (PVC pers. obs.). The psammophilous mayflies are considered to have low population densities and dispersion abilities, making each population unique (McCafferty 1991; Lillie 1995; Glazaczow 1997; Jacobus 2013). Thus, the probability is low that $R$. trichobasis has such a wide distribution, ranging across four Brazilian biomes and in Paraguay.

In order to circumscribe $R$. trichobasis, $R$. coveloae and $R$. venezuelensis, their type material was reevaluated, as well as four of the six records of $R$. trichobasis in Brazil. Our hypothesis is that the lack of information results in a broad diagnosis for species, with many species hidden behind an easily recognizable one.

\section{Material and methods}

\section{Specimens, description and illustration}

Morphological characters of the specimens were used as delimitation criteria. The specimens analyzed in the present study are deposited in the Instituto de Biodiversidad Neotropical (IBN) $-R$. trichobasis LugoOrtiz \& McCafferty, 1998; Instituto Nacional de Pesquisas da Amazônia (INPA) - R. amazona sp. nov., $R$. oxum sp. nov. and $R$. uiara sp. nov.; Universidade Federal de Roraima (UFRR) and Universidade Federal de Viçosa (UFV) - R. naia sp. nov. and $R$. sp. X; and the Purdue Entomological Research Collection (PERC) - R. venezuelensis (Traver, 1943) and $R$. coveloae (Traver, 1971).

The descriptions and measurements were based on the standardized protocol proposed by Hubbard (1995). The photographs of $R$. trichobasis were taken using a cellphone adapted for use with a microscope.

Digital photographs of $R$. amazona sp. nov., $R$. oxum sp. nov., $R$. naia sp. nov. and $R$. uiara sp. nov. were taken using a Leica (M165C) stereo microscope with a DFC420 digital camera, and Leica Application Suite ver. 3.8.0 software, photographs of slides were taken using a cellphone; digital photographs of $R$. venezuelensis and $R$. coveloae were taken using a cellphone. Final illustrations were prepared according to Coleman (2006).

Nymphs were mounted on slides with Euparal ${ }^{\circledR}$ as the mounting medium. Specimens were preserved in ethanol $80 \%$.

\section{Abbreviations in figures}

$$
\begin{aligned}
& \text { d.v. }=\text { dorsal view } \\
& \text { l.v. }=\text { lateral view } \\
& \text { v.v. }=\text { ventral view }
\end{aligned}
$$




\section{Institutional abbreviations}

Samples deposited in the collections of the following museums have been studied:

IBN = Instituto de Biodiversidad Neotropical, Tucumán, Argentina

INPA = Instituto Nacional de Pesquisas da Amazônia, Manaus, Brazil

PERC = Purdue Entomological Research Collection, West Lafayette, United States of America

UFRR = Universidade Federal de Roraima, Boa Vista, Brazil

UFV = Universidade Federal de Viçosa, Viçosa, Brazil

\section{Results}

Class Insecta Linnaeus, 1758

Order Ephemeroptera Hyatt \& Arms, 1891

Family Baetidae Leach, 1815

Subfamily Baetinae Leach, 1815 sensu Cruz et al. (2021)

Genus Rivudiva Lugo-Ortiz \& McCafferty, 1998

Key to the species in the nymphal stage (adapted from Salles \& Nascimento 2009)

1. Abdominal sterna with simple setae; hind wing pads present

2 (minantenna group)

- Abdominal sterna with robust, apically pointed setae (Fig. 3B); hind wing pads absent

2. Setae on dorsum of fore femur long (as long as maximum width of femur) and apically pointed (Salles \& Nascimento 2009: fig. 32)

R. minantenna Lugo-Ortiz \& McCafferty, 1998

- Setae on dorsum of fore femur short (at most $1 / 3$ maximum width of femur) and apically blunt (Salles \& Nascimento 2009: figs 7, 30-31)

R. inma Salles \& Nieto in Salles et al., 2020

3. Scape and pedicel without apically pointed setae; fore tarsus with long setae (Salles \& Nascimento 2009: fig. 17)

R. oonirikoperi Cruz in Salles et al., 2020

- Scape and pedicel with apically pointed setae (Fig. 1A); fore tarsus without long setae

4 (trichobasis group)

4. Labrum with medial emargination (Figs 1B, 12A), hypopharynx with distomedial projection (Figs 1F, $12 \mathrm{~F})$

- Labrum without medial emargination (Figs 4A, 8A, 16A), hypopharynx without distomedial projection (Figs 4F, 8I)

5. Maxillary ventral canine not laterally folded over the canines (Fig. 12D); labial palp segment III wide (Fig. 12G) R. uiara sp. nov. (Central Amazon)

- Maxillary ventral canine laterally folded over the canines (Fig. 1E); labial palp segment III narrow (Fig. 1G) R. trichobasis Lugo-Ortiz \& McCafferty, 1998 (Pampa Biome)

6. Patella-tibial suture on foreleg absent (Fig. 9A); outer arc of setae on glossae sinuous (Fig. 8K); distal lobe of maxillary palp segment II with half of width of segment II apex (Fig. 8D)

R. oxum sp. nov. (Southwestern Amazon)

- Patella-tibial suture on foreleg present (17A); outer arc of setae on glossae not sinuous (Fig. 16G); distal lobe of maxillary palp segment II with the same width of segment II apex (Figs 4E, 16D) ....

7. Segment III of labial palp apically pointed (Fig. 4G); paraproct with nine to eleven marginal spines (Fig. 6B)

R. amazona sp. nov. (Amazon in southern Roraima)

- Segment III of labial palp broadly pointed (Fig. 16F); paraproct with two marginal spines (Fig. 18B) R. naia sp. nov. (ecotone between Amazon forest and Roraima savanna) 
trichobasis species group

\section{Diagnosis}

1) antennal scape and pedicel with long and robust setae (Fig. 1A);2) trochanter with long and robust setae (Fig. 2A, C); 3) distal margin of labrum with two rows of setae, one robust (ventral surface) and one thin and bifid (dorsal surface) (Fig. 1B); 4) maxillary palp segment II with distal lobe (Figs 1E, 8D-H); 5) dorsal surface of glossa with inner arc close to inner margin, outer arc close to outer margin (Figs 4H, $8 \mathrm{~K})$; 6) hindwing pads absent; 7) combination of rows of setae on fore femora: dorsal and ventral margins with long pointed setae, anterior surface with one median row of blunt setae (Figs 2A, 9A, 13A); 8) anterior surface of hind femora with one transversal row of setae at base, with setae sockets not touching each other (Figs 2C, 9C, 13C); 9) abdominal sterna surface with robust, apically pointed setae (Fig. 3B).

\section{Composition}

Rivudiva trichobasis, $R$. amazona sp. nov., $R$. oxum sp. nov., $R$. uiara sp. nov., $R$. naia sp. nov., and R. sp. X.

\section{Rivudiva trichobasis Lugo-Ortiz \& McCafferty, 1998}

Figs $1-3$

Rivudiva trichobasis Lugo-Ortiz \& McCafferty, 1998: 64 (type material).

Rivudiva trichobasis - Cruz et al. 2018: 10, figs 23, 29. - Lugo-Ortiz \& McCafferty 1998: 64 (with some doubt, partim). — Salles et al. 2020: 49 (with some doubt).

not Rivudiva trichobasis - Cruz et al. 2011: 60. - Falcão et al. 2011: 539. — Boldrini et al. 2012: 93. — Boldrini \& Cruz 2014: 5.

Diagnosis (adapted from Salles et al. 2020)

NymPH. The combination of the characters: 1) labrum with medial emargination (Fig. 1B); 2) labrum ventral surface with simple robust row of setae on distal margin (Fig. 1B); 3) left mandible with incisors fused at middle length (Fig. 1C); 4) maxillary palp segment II with robust apical lobe (Fig. 1E); 5) ventral canine expanded, laterally folded over canines; 6) hypopharynx with small distomedial projection (Fig. 1F); 7) outer arc of setae on glossa with apical half not sinuous, far from distal margin (Fig. 1G-H); 8) labial palp segment III narrow and conical (Fig. 1G); 9) dorsal margin of forefemur with one row of long spine-like setae from base to apex (Fig. 2A); 10) forefemur on anterior surface with medial row of elongate blunt setae (Fig. 2A); 11) patella-tibial suture absent; 12) distal margin of terga with wide marginal spines (Fig. 3A).

\section{Material examined}

Paratype

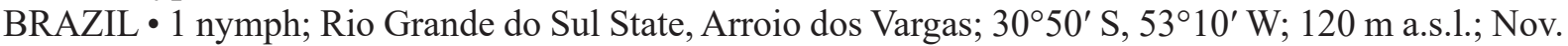
1964; F. Plaumann leg; IBN slide \#270.

\section{Redescription}

\section{Nymph}

HeAD. Antenna (Fig. 1A). Flagellum with minute spines on apex of each segment. Labrum (Fig. 1B). Rectangular, length about $0.7 \times$ maximum width; distal margin with medial emargination, one row of robust, eventually pectinated, setae from lateral to middle; one row of thin bifid setae on distal margin not reaching distolateral margin; dorsal surface, near distal margin, with many thin setae over surface. Left mandible (Fig. 1C). Incisors partially cleft in two sets (fused at middle length); outer and inner set of incisors respectively with $4+3$ denticles, outer incisor without spine-like process; prostheca robust 

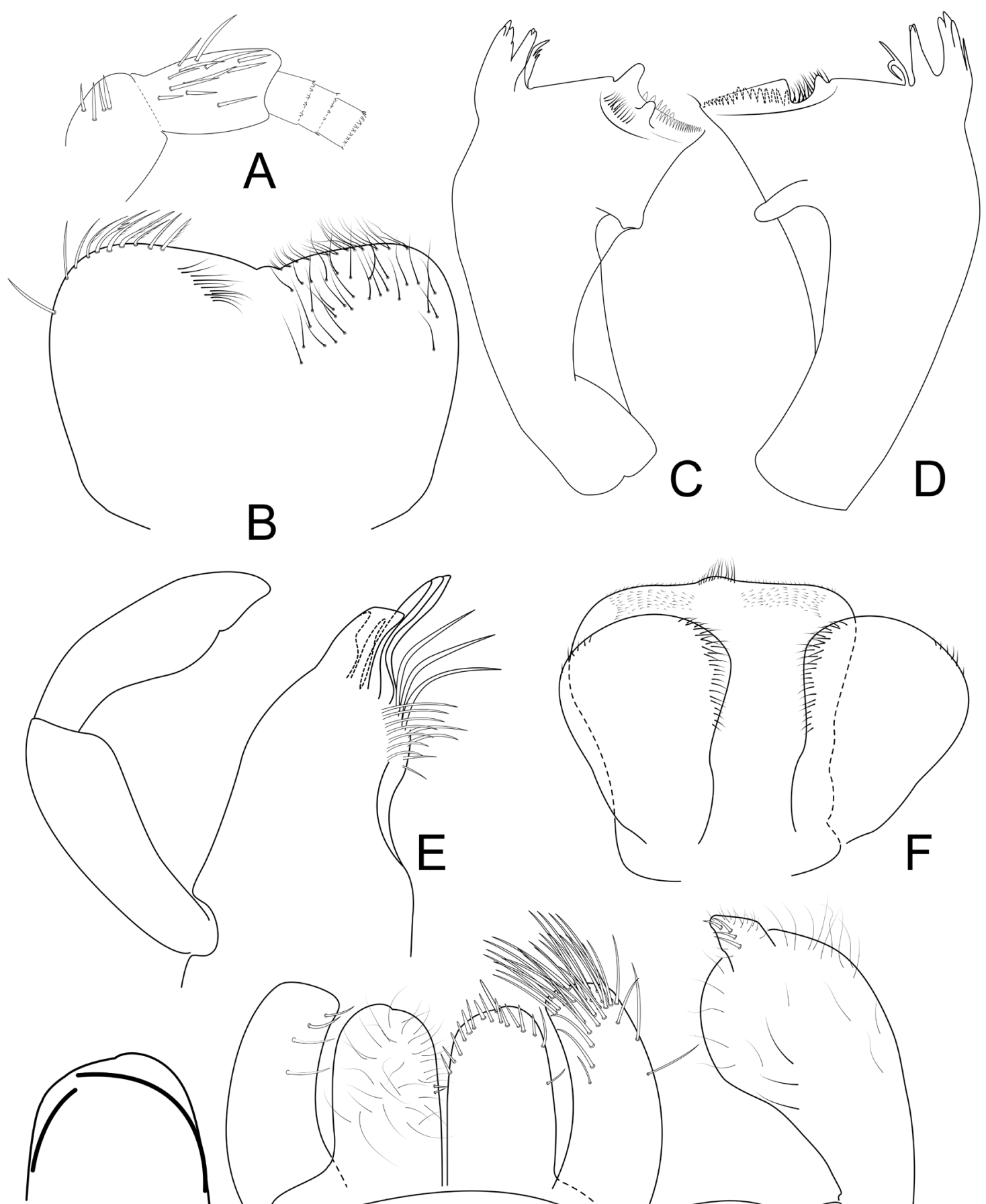

$\mathrm{H}$



Fig. 1. Rivudiva trichobasis Lugo-Ortiz \& McCafferty, 1998, paratype (IBN slide \#270). A. Scape and pedicel. B. Labrum (left v.v., right d.v.). C. Left mandible. D. Right mandible. E. Apex of maxilla (base was deformed in slide). F. Hypopharynx. G. Labium (left v.v., right d.v.). H. Shape of distal rows of setae of glossa. Not to scale. 
and apically pectinate; margin between prostheca and mola straight; tuft of spine-like setae at base of mola absent; subtriangular process wide; denticles of mola not constricted; mola with one large denticle; outer margin convex. Right mandible (Fig. 1D). Incisors fused at base; outer and inner set of incisors respectively with $3+3$ denticles, outer incisor with one spine-like process; prostheca stout, bifurcated at middle, inner lobe longer and pectinate; margin between prostheca and mola straight; tuft of spine-like setae at base of mola present; denticles of mola not constricted; apex of mola with one simple setae; first process of mola triangular, second expanded and straight; outer margin convex. Maxilla (Fig. 1E). Maxillary palp $1.6 \times$ length of galea-lacinia; segment II $1.0 \times$ length of segment I, apex with robust apical lobe; ventral canine expanded, laterally folded over canines; set of distal setae of inner-ventral row clavate, base of maxilla broken. Hypopharynx (Fig. 1F). Lingua longer than superlingua, sub-quadrangular with a small distomedial projection covered by tuft of simple setae; superlingua with rounded outer margin; short, thin, simple setae scattered over distal margin of lingua and superlingua. Labium (Fig. 1G-H). Glossa slightly broad at base, with parallel margins, distal margin slightly rounded with small concavity and shorter than paraglossa; inner margin with two short spine-like setae on half; ventral surface covered by thin setae; dorsal surface with inner arc close to inner margin, outer arc basal half of row close to outer margin, apical half of row not sinuous, far from distal margin; one long robust blunt seta on apex. Paraglossa curved inward; apex with two rows of robust and long spine-like setae; outer margin with two long setae; dorsal surface with three longitudinal rows of setae, first row near inner margin longer than half of length, with long robust setae; second with half of length of the inner row, with long robust setae; and third near to outer-distal margin, with long setae, ventral surface with one row of four setae near to ventral margin. Labial palp with segment I $0.8 \times$ length of segments II and III combined; inner distal protuberance of segment II rounded, covered with thin, long simple setae; segment III narrow and conical (folded in slide studied), covered by thin simple setae, dorsal surface with robust spine-like setae near inner margin.

Thorax. Foreleg (Fig. 2A-C). Femur length about $3.2 \times$ maximum width; anterior surface with one medial row of elongate and blunt setae, one row of long spine-like setae near ventral margin not reaching apex; posterior surface with one row of long spine-like setae near dorsal margin not reaching apex, and one row of long spine-like setae near ventral margin reaching apex. Tibia. Dorsally bare; ventral margin with one row of long spine-like setae increasing in length to apex; patella-tibial suture absent. Tarsus. Ventral margin with one row of spine-like setae. Tarsal claws (Fig. 2B) $0.3 \times$ length of tarsus, with two rows of conical denticles not reaching apex. Hind leg (Fig. 2D-E). Femur anterior surface with one row of spine-like setae near dorsal margin on distal half, one row of long spine-like setae near ventral margin; posterior surface with one row of long spine-like setae near dorsal margin not reaching apex, one row of spine-like setae near ventral margin reaching apex. Tibia. Dorsally bare; ventral margin with one row of small blunt setae; patella-tibial suture present. Tarsus. Ventral margin with one row of small blunt setae. Tarsal claws (Fig. 2D) $0.5 \times$ length of tarsus, with two rows of small conical denticles reaching apex.

AbDomen. Terga III and VI with large medium brown mark. Posterior margin of terga with small triangular spines (Fig. 3A-B). Gills missing. Paraproct (Fig. 3C) with nine to twelve wide marginal spines, posterolateral extension with spines. Cerci (Fig. 3D) with lateral spines on every segment. Paracercus (Fig. 3E) without spines.

\section{Comments}

Based on the study of type material, records from Brazil, Roraima (Falcão et al. 2011), Rondônia (Boldrini \& Cruz 2012), Amazonas (Cruz et al. 2011) and Maranhão (R. sp. X) (Boldrini et al. 2012), are not $R$. trichobasis. The specimens from Espírito Santo (Brazil) (Salles et al. 2020) and Paraguay (Paraguarí) could not be evaluated.

\section{Distribution}

Brazil (Rio Grande do Sul). Paraguay (Paraguarí) is treated here as putative; records from Espírito Santo (Brazil) (Salles et al. 2020) are treated here as putative and must be evaluated. 


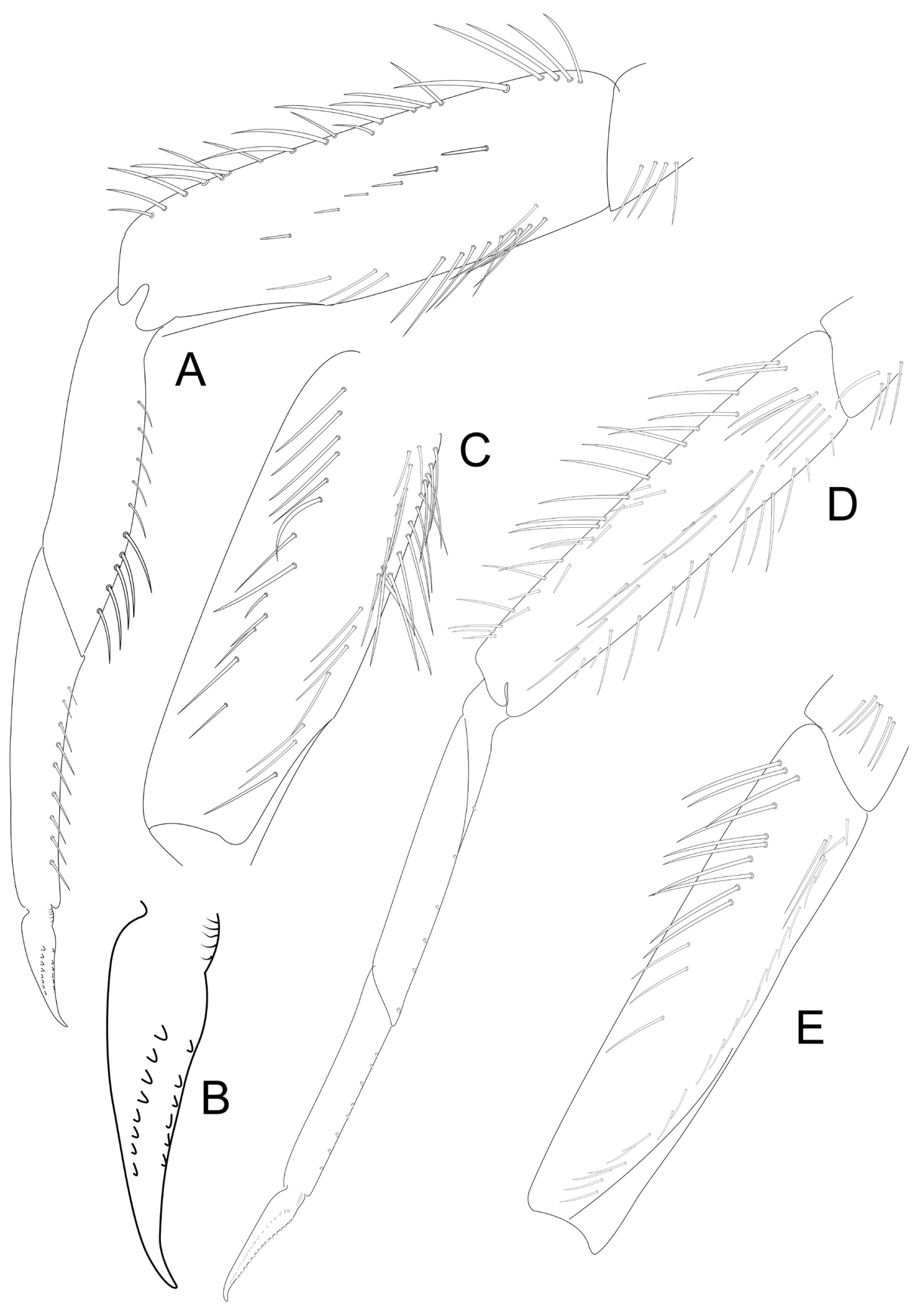

Fig. 2. Rivudiva trichobasis Lugo-Ortiz \& McCafferty, 1998, paratype (IBN slide \#270). A. Foreleg (femur on anterior surface). B. Detail of fore claw. C. Posterior surface of forefemur. D. Hind leg. E. Posterior surface of hind femur. Not to scale. 




A
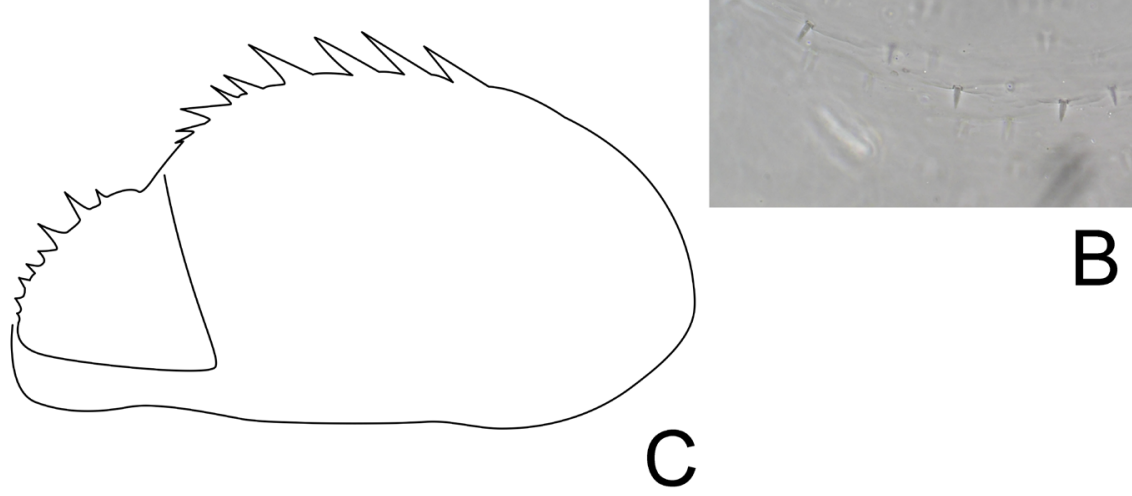

C
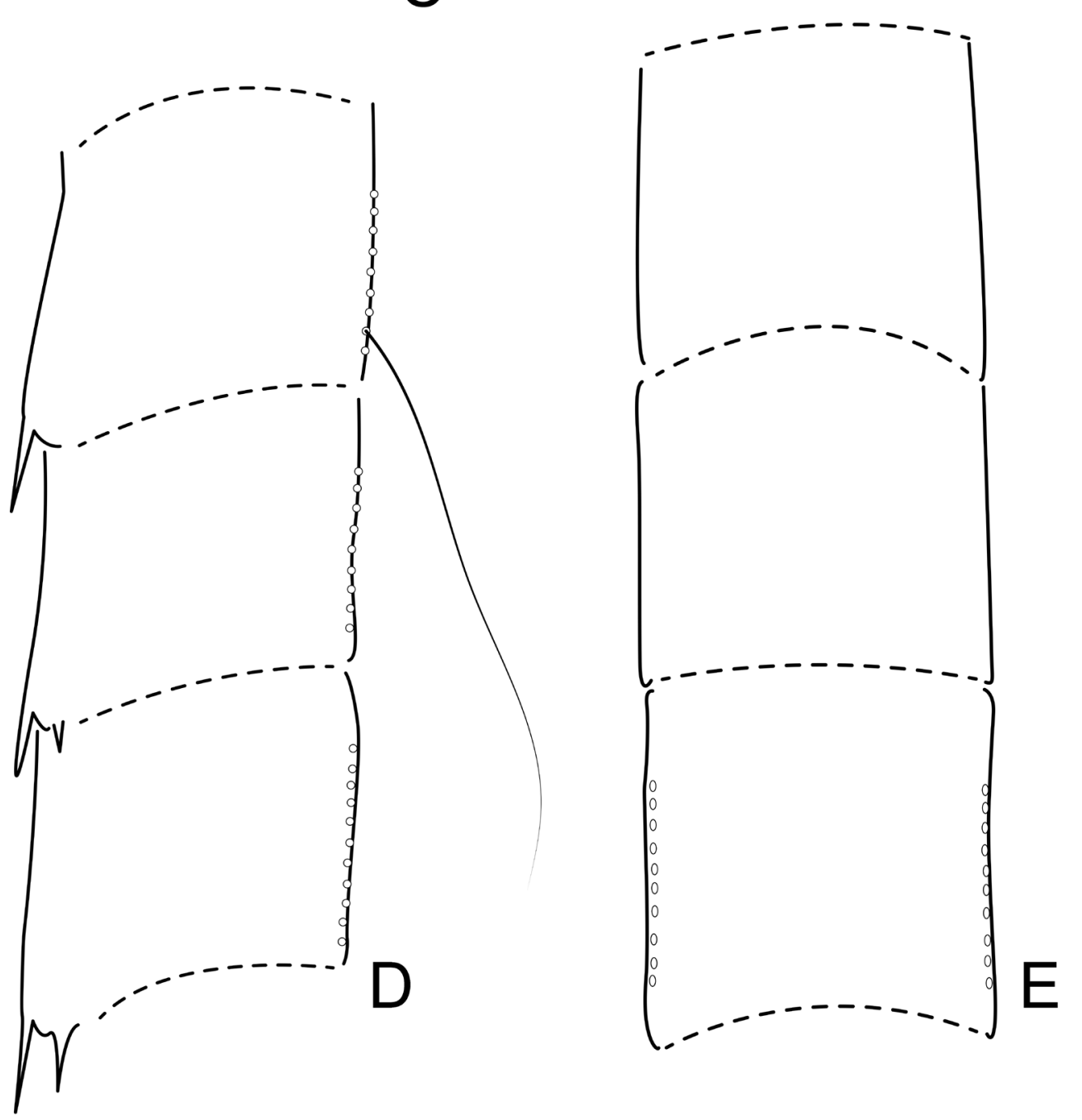

Fig. 3. Rivudiva trichobasis Lugo-Ortiz \& McCafferty, 1998, paratype (IBN slide \#270). A. Margin of tergum IV. B. Surface of sternum IV. C. Paraproct. D. Cercus. E. Paracercus. Not to scale. 


\section{Rivudiva amazona sp. nov. urn:1sid:zoobank.org:act:595B6165-BC4E-4AFB-BF4F-CD6FB5C22432}

Figs 4-7

Rivudiva trichobasis - Falcão et al. 2011: 539.

\section{Diagnosis}

NyMPH. The combination of the characters: 1) labrum with distal margin straight (Fig. 4A); 2) labrum ventral surface with robust, distally bifid, eventually pectinated, setae on distal margin (Fig. 4A); 3) left mandible with incisors fused at basal third (Fig. 4B); 4) maxillary palp segment II with reduced apical lobe (Fig. 4D); 5) hypopharynx without distomedial projection (Fig. 4F); 6) glossa oval with inner and outer arcs of setae not sinuous and close to margins (Fig. 4G-H); 7) labial palp segment III robust, conical and apically pointed (Fig. 4G); 8) dorsal margin of forefemur with one row of long setae from middle length to apex (Fig. 5A); 9) forefemur on anterior surface with long blunt setae at middle (Fig. 5A); 10) patella-tibial suture present; 11) distal margin of terga with elongated triangular spines (Fig. 6A).

\section{Etymology}

The name 'Amazonas' was given to native South American women after they attacked a conquest expedition. This species is named in honor of these brave native women. Name in apposition.

\section{Material examined}

\section{Holotype}

BRAZIL • nymph on slide; Roraima, Caroebe, River Caroebe, vicinal 05; 0054'47.3" N, 59³4'19.9" W; 19 Mar. 2013; P.V. Cruz, N. Hamada, R. Boldrini and G. Petronilo leg.; sand; INPA.

\section{Paratypes}

BRAZIL $・ 14$ nymphs; same collection data as for holotype; INPA $\bullet 2$ nymphs on slide; same locality as for holotype; 12 Mar. 2018; P.V. Cruz and I.O. Fernandes leg.; sand; INPA.

\section{Additional material}

BRAZIL - 4 nymphs; Roraima, BR-170, $41 \mathrm{Km}$ turn to BR-432, old bridge, right from Vila de Santa Rita; 0208'59.9" N, 6040'39.9" W; 28 Mar. 2012; P.V. Cruz, N. Hamada, R. Boldrini and G. Petronilo

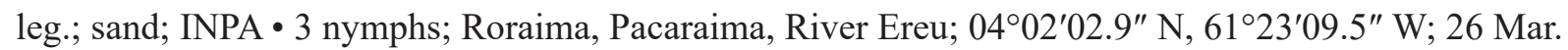
2012; P.V. Cruz, N. Hamada, R. Boldrini and G. Petronilo leg.; INPA • 3 nymphs; Roraima, São João da Baliza, Ramal 27, stream Lajinha; 0100'59.7" N, 5955'53.1" W; 24 Mar. 2012; P.V. Cruz, N. Hamada, R. Boldrini and G. Petronilo leg.; INPA - 1 nymph; Roraima, Caroebe, Ramal 37, River Caroebe, Cachoeirinha farm; 0057'09.2" N, 59³7'00.5" W; 23 Mar. 2012; P.V. Cruz, N. Hamada, R. Boldrini and G. Petronilo leg.; INPA.

\section{Description}

\section{Nymph}

LeNGTH. Body, 3.3-3.5 mm.

HEAD. Antenna. Scape and pedicel with spine-like setae; flagellum with minute spines on apex of each segment. Labrum (Fig. 4A). Rectangular, length about $0.6 \times$ maximum width; distal margin straight, one row of robust, distally bifid, eventually pectinated, setae from lateral to middle of distal margin; one row of thin bifid setae on distal margin not reaching distolateral margin; dorsal surface, near distal margin, with one row of thin setae, and many thin setae over surface (not illustrated). Left mandible (Fig. 4B). Incisors partially cleft in two sets (fused at basal third); outer and inner sets of incisors respectively with $4+3$ denticles, outer incisor with spine-like process; prostheca robust and pectinated; margin between prostheca 


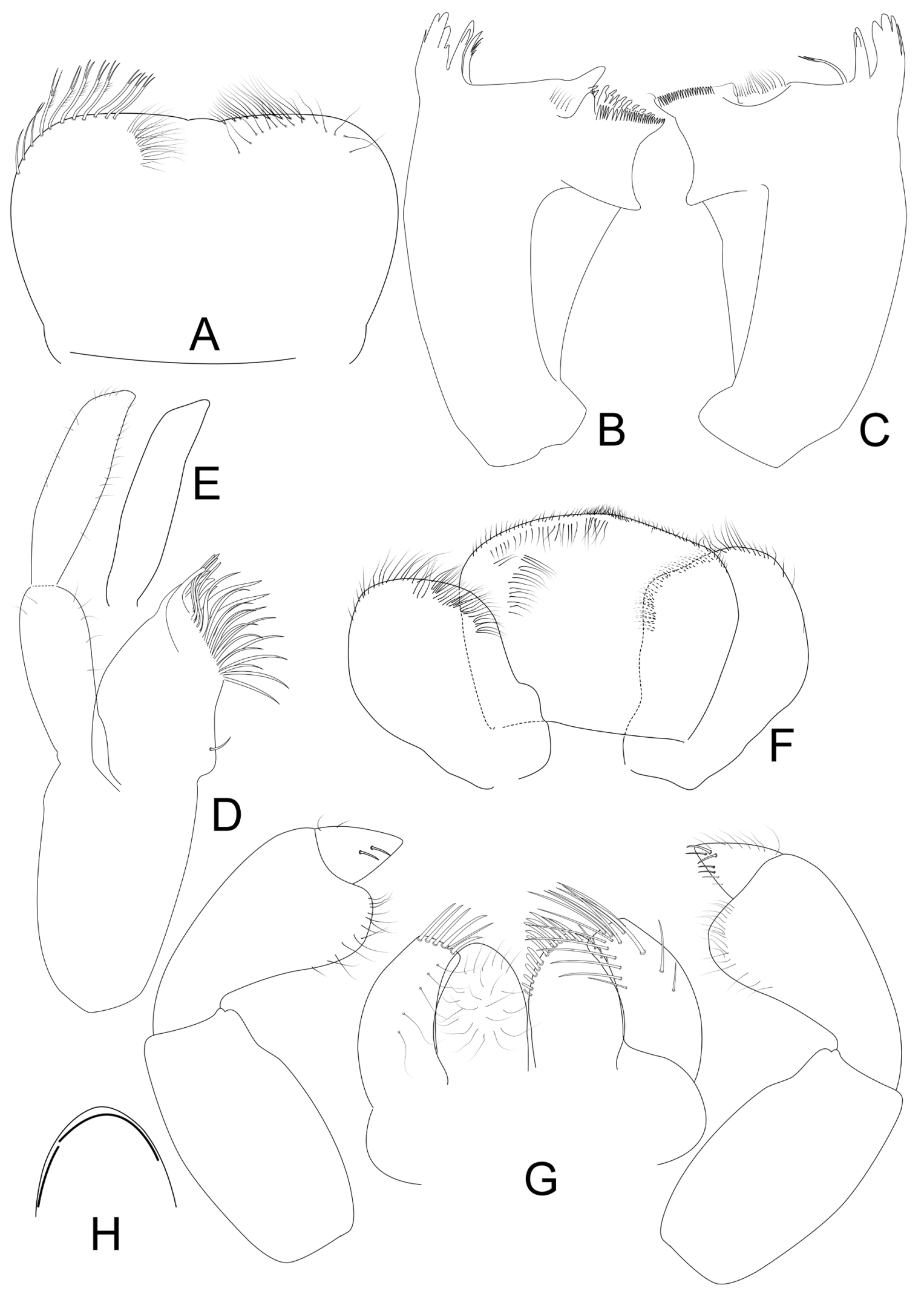

Fig. 4. Rivudiva amazona sp. nov., holotype (INPA). A. Labrum (left v.v., right d.v.). B. Left mandible. C. Right mandible. D. Left maxilla. E. Variation of maxillar palp segment II (right maxilla). F. Hypopharynx. G. Labium (left v.v., right d.v.). H. Shape of distal rows of setae of glossa. Not to scale. 
and mola straight; tuft of spine-like setae at base of mola present; subtriangular process wide; denticles of mola constricted; mola with one large denticle; outer margin convex. Right mandible (Fig. 4C). Incisors fused at base; outer and inner sets of incisors respectively with $3+3$ denticles, outer incisor with spinelike process; prostheca stout, bifurcated at apex, inner lobe longer; margin between prostheca and mola almost straight; tuft of spine-like setae at base of mola present; denticles of mola not constricted; apex of mola with one simple setae; first process of mola rounded, second expanded and straight; outer margin convex. Maxilla (Fig. 4D-E). Maxillary palp $1.7 \times$ length of galea-lacinia; segment II $1.1 \times$ length of segment I; segment II inner margin straight, outer margin on apex straight, reduced apical lobe; ventral canine enlarged, not laterally expanded; set of distal setae of inner-ventral row rounded. Hypopharynx (Fig. 4F). Lingua longer than superlingua, sub-quadrangular without distomedial projection covered by tuft of simple setae; superlingua with rounded outer margin; short, thin, simple setae scattered over distal margin of lingua and superlingua. Labium (Fig. 4G-H). Glossa oval, slightly broad at base, distally rounded, shorter than paraglossa; inner margin without row of setae; ventral surface covered by thin setae; dorsal surface with inner arc close to inner margin, and outer arc not sinuous and close to outer margin; one small robust blunt seta on apex. Paraglossa curved inward; apex with one row of robust and long spine-like setae; outer margin without setae; dorsal surface with two longitudinal rows of setae, one near to inner margin, one near to outer margin, distally with long robust setae; ventral surface with one row of five setae near to ventral margin. Labial palp with segment I $0.8 \times$ length of segments II and III combined; inner distal protuberance of segment II rounded, with almost straight distal margin, covered with thin setae; segment III robust, conical, and apically pointed; outer margin with short thin setae, dorsal surface with one row of short spine-like setae near inner margin, ventral surface with one row of setae.

ThORAX. Foreleg (Fig. 5A-C). Femur length about $2.6 \times$ maximum width; dorsal row of setae from distal half to apex; anterior surface with one medial row of long blunt setae, one row of short blunt setae near dorsal margin; posterior surface with one row of long spine-like setae near ventral margin from base to apex, and one medial row of long spine-like setae. Tibia. Dorsally bare; ventral margin with one row of long spine-like setae, patella-tibial suture present. Tarsus. Ventral margin with one row of spine-like setae. Tarsal claws $0.4 \times$ length of tarsus, with two rows of conical denticles not reaching apex. Hind leg (Fig. 5D-E). Femur anterior surface with one row of spine-like setae near dorsal margin reaching apex, one row of long spine-like setae near ventral margin reaching apex, one row of spine-like setae near middle; posterior surface with one row of spine-like setae near ventral margin from base to apical third. Tibia. Dorsally bare; ventral margin with one row of small blunt setae, patella-tibial suture present. Tarsus. Ventral margin with one row of small blunt setae. Tarsal claws $0.4 \times$ length of tarsus, with two rows of small conical denticles not reaching apex.

AbDomen. Terga (Fig. 7) with all segments white (color lost in alcohol), terga I-IX with two small medial dots, sometimes dots absent; tergum I with one large dot on disto-lateral margin (rare); eventually tergum II, III and IX darker or with large brown pigmentation; terga III and VI with one large medial mark near distal margin; terga VI and VII with disto-lateral transversal brown mark (rare). Posterior margin of terga with elongated triangular spines (Fig. 6A). Gills oblong, longer than next segment, with one medial trachea pigmented. Paraproct (Fig. 6B) with nine to eleven marginal spines, posterolateral extension with spines (broken in holotype and illustrated). Cerci (Fig. 6C) with lateral spines on every segment. Paracercus (Fig. 6D) without spines.

\section{Comments}

The differences in deepness of the curvature of the distal lobe on the maxillary palp segment II is related to the slide artifact (Fig. 4E). 


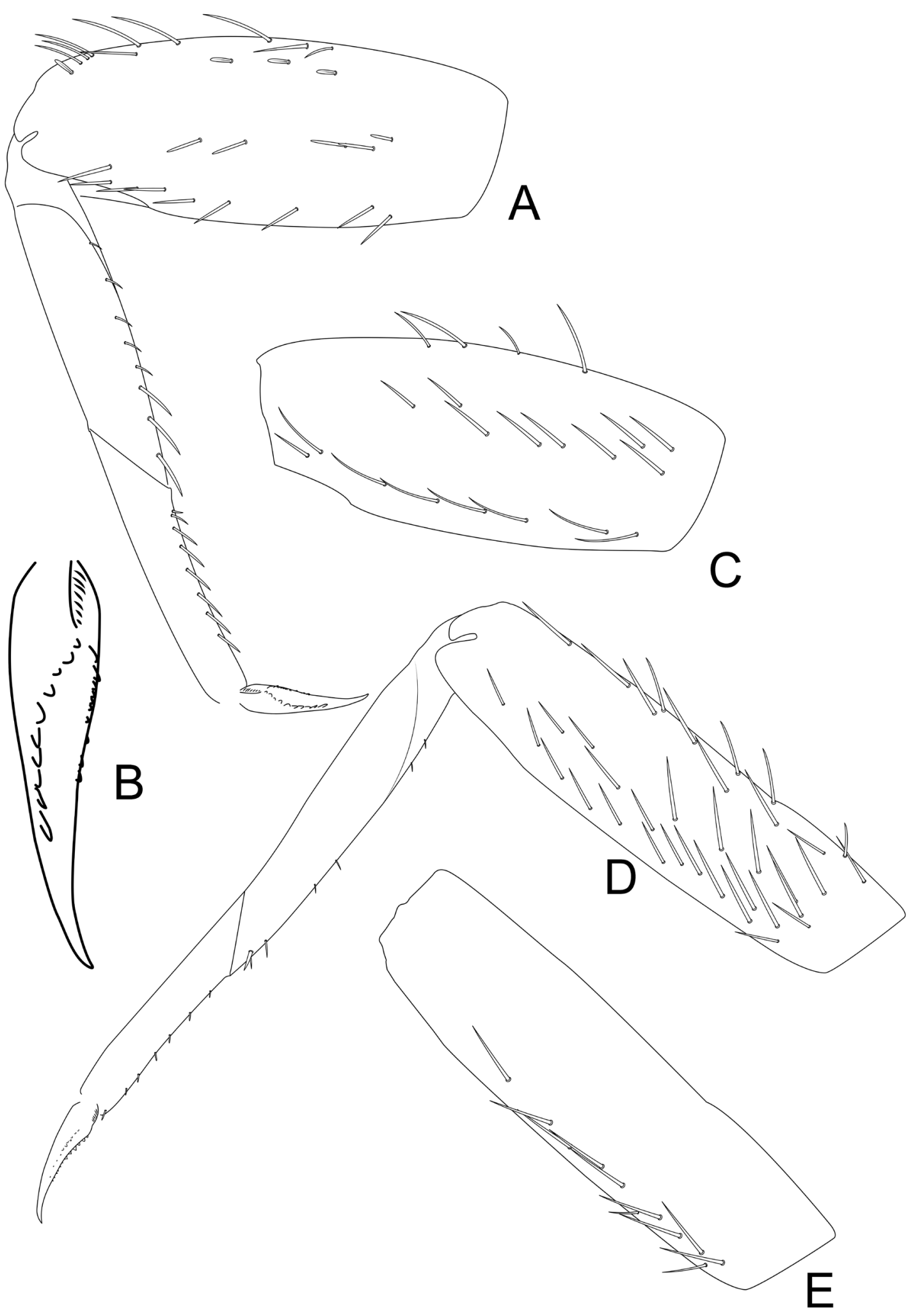

Fig. 5. Rivudiva amazona sp. nov., holotype (INPA). A. Foreleg (femur on anterior surface). B. Detail of fore claw. C. Posterior surface of forefemur. D. Hind leg (femur on anterior surface). E. Posterior surface of hind femur. Not to scale. 



Fig. 6. Rivudiva amazona sp. nov., holotype (INPA). A. Margin of tergum IV. B. Paraproct. C. Cercus. D. Paracercus. Not to scale. 


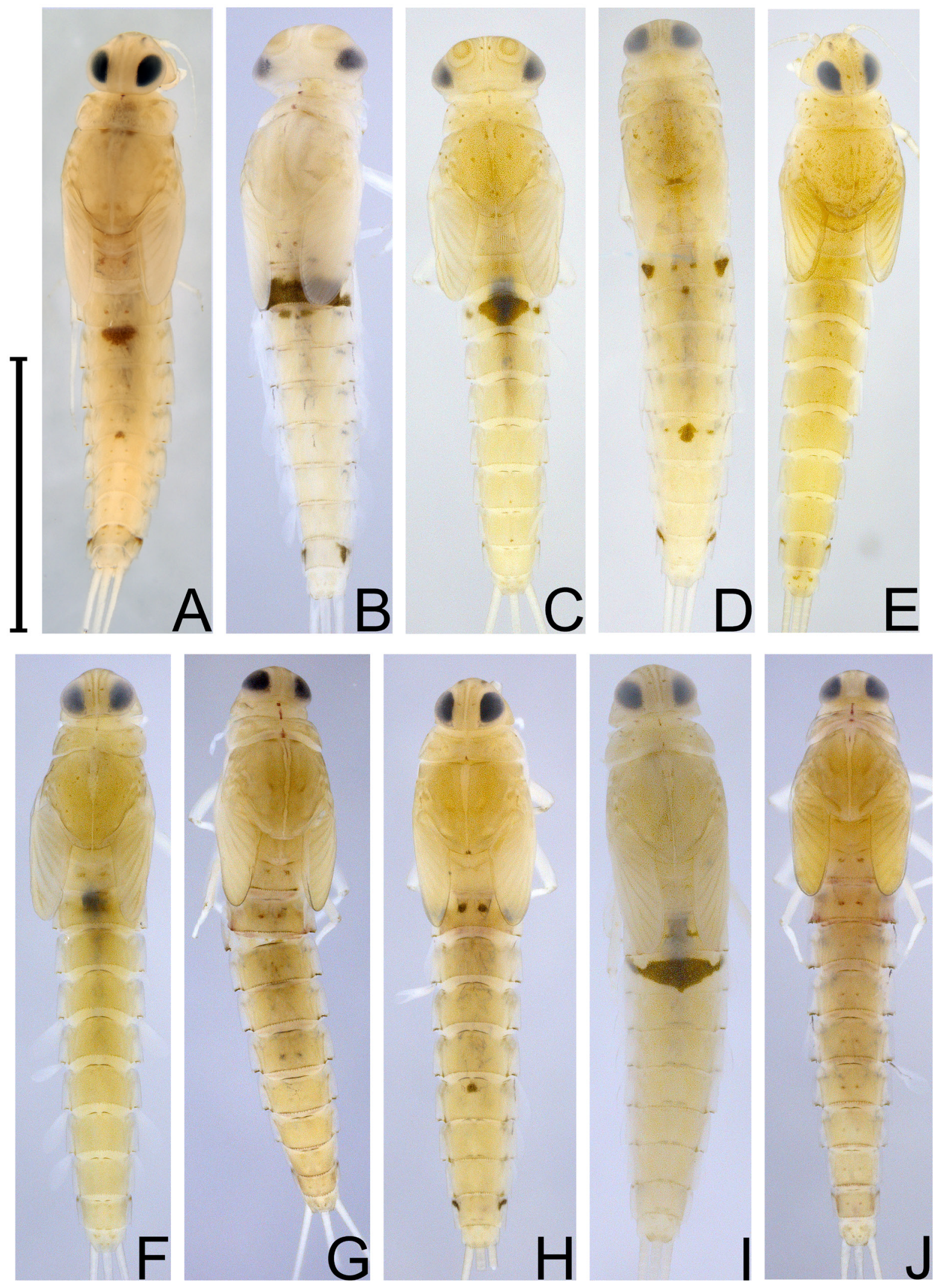

Fig. 7. Rivudiva amazona sp. nov., dorsal habitus of nymphs, variation of pigmentation pattern. A. Holotype (INPA). B-J. Paratypes (INPA). Scale bar $=1.65 \mathrm{~mm}$. 


\section{Rivudiva oxum sp. nov. urn:1sid:zoobank.org:act:21BF614C-3B80-4307-82BE-F981DE45D244}

Figs 8-11

Rivudiva trichobasis - Boldrini \& Cruz 2014: 5. — Salles et al. 2020: 49.

\section{Diagnosis}

NyмPH. The combination of the characters: 1) labrum distal margin straight (Fig. 8A); 2) labrum ventral surface with robust, distally bifid, eventually pectinated, setae on distal margin (Fig. 8A); 3) left mandible with incisors fused at middle (Fig. 8B); 4) maxillary palp segment II with inner distal protuberance, outer margin straight, with long distal lobe (Fig. 8D-H); 5) hypopharynx without distomedial projection (Fig. 8I); 6) glossae inner arc of setae following the inner margin at base, curved at apex, outer arc of setae sinuous (Fig. 8J-K); 7) labial palp segment III robust, conical and apically pointed (Fig. 8J); 8) dorsal margin of forefemur with one row of long setae from base to apex (Fig. 9A); 9) anterior surface of forefemur with blunt setae at middle (Fig. 9A); 10) patella-tibial suture absent; 11) distal margin of terga with triangular spines (Fig. 10A).

\section{Etymology}

'Oxum' is a female 'orixá' (deity or goddess) from the Ijexá nation, adopted and worshipped in AfroBrazilian religions. She is the fresh waters 'orixá' (lakes, rivers and waterfalls), of wealth, love, prosperity and beauty. Name in apposition.

\section{Material examined}

\section{Holotype}

BRAZIL • nymph on slide; Rondônia, Alto Alegre dos Parecis, line 24 southbound from RO-370 leaving Alto Alegre to the east, under the bridge; $12^{\circ} 12^{\prime} 57.8^{\prime \prime}$ S, 061 ${ }^{\circ} 47^{\prime} 18.4^{\prime \prime} \mathrm{W} ; 8$ Jul. 2016; P.V. Cruz leg.; INPA.

\section{Paratypes}

BRAZIL • 3 nymphs; same collection data as for holotype; INPA $\bullet 3$ nymphs; Rondônia, Machadinho do Oeste, RO-133 between Tabajara and 2 de novembro streams; 08 $53^{\prime} 10.0^{\prime \prime}$ S, 062 $11^{\prime} 21.8^{\prime \prime}$ W; 21 Aug. 2016; P.V. Cruz and N. Hamada leg.; INPA • 1 nymph; Rondônia, Alto Alegre dos Parecis, line 24 southbound from RO-370 leaving Alto Alegre to the east, at the curve at the foot of a hill; $12^{\circ} 14^{\prime} 22.8^{\prime \prime} \mathrm{S}$, 061 ${ }^{\circ}$ 4'26.9" W; 9 Jul. 2016; P.V. Cruz and N. Hamada leg.; INPA • 5 nymphs; Rondônia, Alto Alegre dos Parecis, line 24 southbound from RO-370 leaving Alto Alegre to the east, at the curve at the foot of a hill; 12 $14^{\prime} 23.2^{\prime \prime}$ S, 061 ${ }^{\circ} 47^{\prime} 26.7^{\prime \prime}$ W; 8 Jul. 2016; P.V. Cruz and N. Hamada leg.; INPA • 2 nymphs; same locality as for preceding; 24 Jul. 2016; P.V. Cruz and N. Hamada leg.; INPA • 6 nymphs; Rondônia, Alto Alegre dos Parecis, line 24 southbound from RO-370 leaving Alto Alegre to the east, preserved area of PCH Santa Luzia, small stream; 12²0'37.4" S, 061 ${ }^{\circ} 45^{\prime} 26.3^{\prime \prime}$ W; 9 Jul. 2016; P.V. Cruz leg.; INPA • 1 nymph; Rondônia, Nova União, Vale da Cachoeiras, Balneário, access by RO-470 or RO-473, below

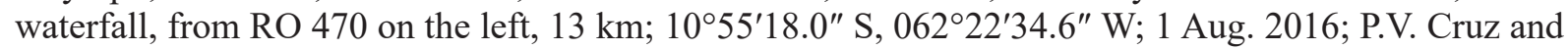
N. Hamada leg.; INPA • 4 nymphs; Amazonas, Humaitá, PARNA Campos Amazônicos, Veado stream; 08²6'27.4" S, 061³9'37.3" W; 6 Jul. 2018; P.V. Cruz, N. Hamada and G. Desidério leg.; INPA.

\section{Description}

Nymph

LENGTH. Body, 3.3-3.5 mm.

HEAD. Antenna. Flagellum with minute spines on apex of each segment. Labrum (Fig. 8A). Rectangular, length about $0.6 \times$ maximum width; distal margin straight; one row of robust, distally bifid, eventually pectinated, setae from lateral to middle of distal margin; one row of thin bifid setae on distal margin not reaching distolateral margin; dorsal surface with many thin setae over surface. Left mandible (Fig. 8B). Incisors partially cleft in two sets (fused at middle); outer and inner sets of incisors respectively with $4+3$ 
denticles, outer incisor with spine-like process; prostheca robust and pectinated; margin between prostheca and mola straight; tuft of spine-like setae at base of mola present; subtriangular process wide; denticles of mola constricted; mola with two large denticles, apex of mola with one simple seta; outer margin convex. Right mandible (Fig. 8C). Incisors fused at base; outer and inner sets of incisors respectively with $3+$ 3 denticles, outer incisor with spine-like process; prostheca stout, bifurcated at apex, inner lobe longer; margin between prostheca and mola almost straight; tuft of spine-like setae at base of mola present; denticles of mola not constricted; apex of mola with one simple seta; first process of mola rounded, second expanded and straight; outer margin convex. Maxilla (Fig. 8D-H). Maxillary palpi $1.7 \times$ length of galea-lacinia; segment II $0.9 \times$ length of segment I; segment II with inner distal protuberance, outer margin straight, with long distal lobe half of width of segment II apex; ventral canine enlarged, not laterally expanded; set of distal setae of the inner-ventral row rounded. Hypopharynx (Fig. 8I). Lingua longer than superlingua, sub-quadrangular, without distomedial projection, with medio-distal tuft of simple setae; superlingua with rounded outer margin; short, thin, simple setae scattered over distal margin of lingua and superlingua. Labium (Fig. 8J-K). Glossa slightly expanded at base, with parallel margins, distal margin slightly rounded, shorter than paraglossa; inner margin without row of setae; ventral surface covered by thin setae; dorsal surface with inner arc of robust pointed setae following the inner margin at base, curved at apex, outer arc of long robust setae following the inner margin at base, sinuous at apex; one small robust blunt seta on apex. Paraglossa curved inward; apex with one row of robust and long spine-like setae; outer margin without setae; dorsal surface with four longitudinal rows of setae, inner row longer than half of length of paraglossa, distally with long robust setae; ventral surface with one row of six setae near to inner margin, apex with one row of robust setae. Labial palp with segment I $0.8 \times$ length of segments II and III combined; inner distal protuberance of segment II rounded, covered with thin setae; segment III robust, conical, and apically pointed; outer margin with short thin setae, dorsal surface covered with short spine-like setae, ventral surface with two short spine-like setae, and covered by long thin setae.

ThORAX. Foreleg (Fig. 9A-C). Femur length about $3.3 \times$ maximum width; dorsal margin with one row of long spine-like setae from base to apex; anterior surface with one medial row of blunt setae, one row of long spine-like setae near ventral margin reaching apex, one row of long spine-like setae near dorsal margin; posterior surface with one row of long spine-like setae near ventral margin from base to apex, and one medial row of long spine-like setae from base to apical third. Tibia. Dorsally bare; ventral margin with one row of long spine-like setae at apical half, patella-tibial suture absent. Tarsus. Ventral margin with one row of spine-like setae. Tarsal claws $0.5 \times$ length of tarsus, with two rows of small conical denticles not reaching apex. Hind leg (Fig. 9D-E). Femur dorsal margin with one row of long spine-like setae; anterior surface with one row of spine-like setae near dorsal margin, one row of long spine-like setae near ventral margin, one row of spine-like setae near middle; posterior surface with one row of spine-like setae near ventral margin. Tibia. Dorsally bare; ventral margin with two small blunt setae base, patella-tibial suture present. Tarsus. Ventral margin with one row of small blunt setae. Tarsal claws $0.6 \times$ length of tarsus, with two rows of small conical denticles reaching apex.

AвDOMEn. Terga (Fig. 11) with all segments yellowish or white (color lost in alcohol), terga I-VIII with two small medial dots, sometimes dots absent; terga III and VIII with one large dot on distal margin (eventually absent); tergum IX darker. Posterior margin of terga with triangular spines (Fig. 10A). Gills oblong, longer than next segment, with one medial trachea pigmented. Paraproct (Fig. 10B) with seven to nine marginal spines, posterolateral extension with spines. Cerci (Fig. 10C) with lateral spines on every segment. Paracercus (Fig. 10D) without spines.

\section{Comments}

The variation presented in Fig. 8E-F is related to the slide mount artifact. In Fig. 8E, the maxillary palp is in outer margin view, while in Fig. $8 \mathrm{G}-\mathrm{H}$ it is in lateral view. The palps presented in Fig. $8 \mathrm{G}-\mathrm{H}$ are true variations of the segment II and its distal lobe. 



Fig. 8. Rivudiva oxum sp. nov. A-D, I-K. Holotype (INPA). E-H. Paratypes (INPA). A. Labrum (left v.V., right d.v.). B. Left mandible. C. Right mandible. D. Maxilla. E-H. Variation of maxillar palp segment II ( E-F is related to slide mounting). I. Hypopharynx. J. Labium (left v.v., right d.v.). K. Shape of distal rows of setae of glossa. Not to scale. 

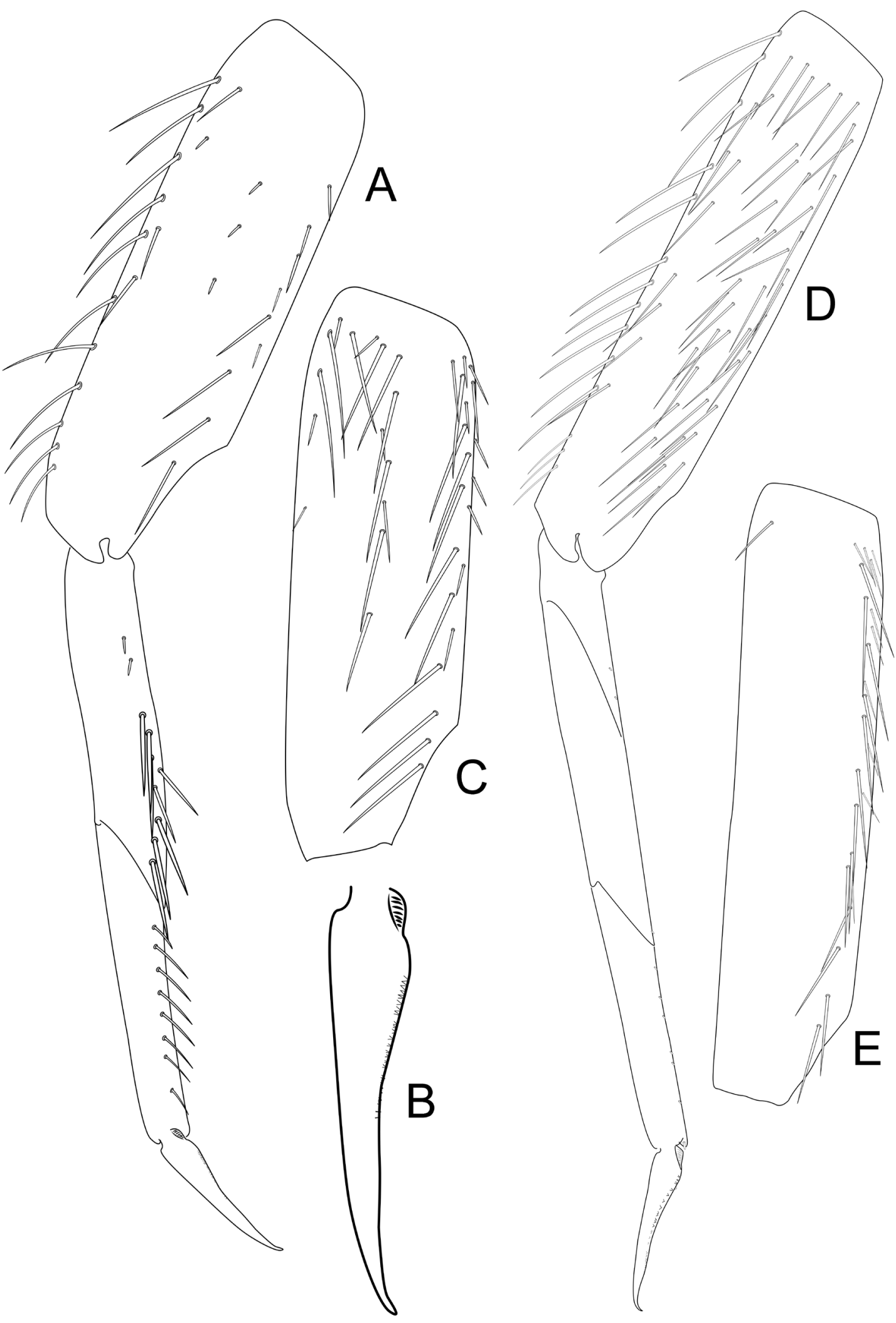

Fig. 9. Rivudiva oxum sp. nov., holotype (INPA). A. Foreleg (femur on anterior surface). B. Details of fore claw. C. Posterior surface of forefemur. D. Hind leg (femur on anterior surface). E. Posterior surface of hind femur. Not to scale. 




A
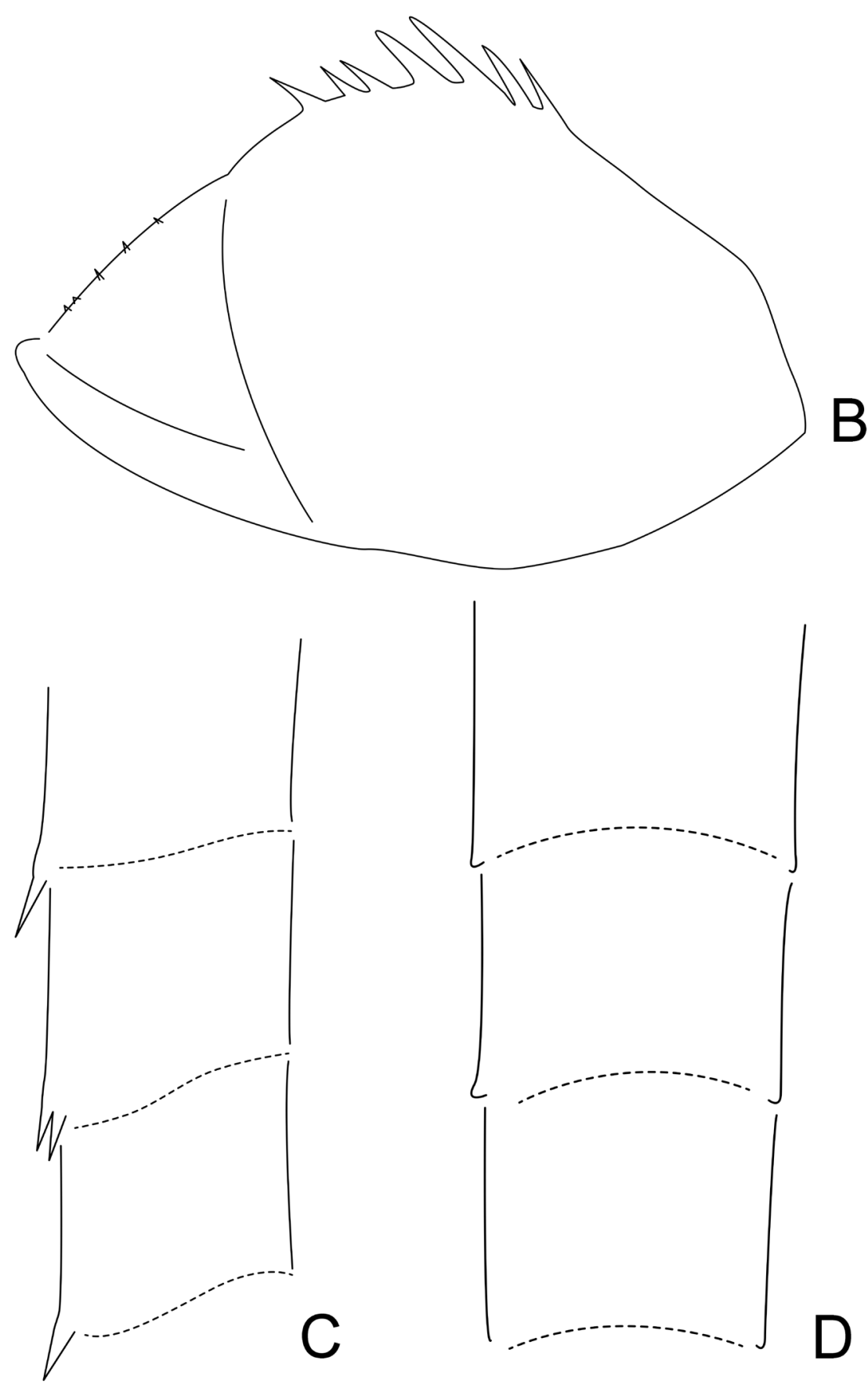

Fig. 10. Rivudiva oxum sp. nov., holotype (INPA). A. Margin of tergum IV. B. Paraproct. C. Cercus. D. Paracercus. Not to scale. 



Fig. 11. Rivudiva oxum sp. nov., dorsal habitus of nymphs, variation of pigmentation pattern. A. Holotype on slide (INPA). B-I. Paratypes (INPA). Scale bar $=1.65 \mathrm{~mm}$. 


\section{Rivudiva uiara sp. nov. urn:1sid:zoobank.org:act:29E9AB92-89A4-43CB-AD13-9F84C3C78F4C}

Figs $12-15$

Rivudiva trichobasis - Cruz et al. 2011: 60 .

\section{Diagnosis}

IMAGO (adapted from Cruz et al. 2011). 1) dorsal portion of turbinate eyes with inner margins not parallel, divergent distally (Cruz et al. 2011: figs 1-2); 2) length of forewing about 3.7× width (Cruz et al. 2011: fig. 3); 3) hind wings absent; 4) terga III and VI of abdomen with one large medial red mark near distal margin (Cruz et al. 2011: figs 4-5); 5) unistyliger cylindrical (Cruz et al. 2011: fig. 6); 6) first segment of gonostylus short, length less than half of second segment, third segment clavate (Cruz et al. 2011: fig. 6); 7) styliger plate concave, without spine (Cruz et al. 2011: fig. 6); 8) gonovectis short, sinuous, not deep into segment IX.

NymPH. The combination of the characters: 1) labrum with small medial emargination (Fig. 12A); 2) labrum ventral surface with simple or pectinated robust setae on distal margin (Fig. 12A); 3) left mandible with incisors fused at basal third (Fig. 12B); 4) maxillary palp segment II with small apical lobe (Fig. 12D); 5) hypopharynx with distomedial projection, lateral area of distomedial projection excavated (Fig. 12F); 6) inner arc of setae of glossa close to inner margin, outer arc of setae sinuous (Fig. 12G-I); 7) labial palp segment III conical, inner margin on basal half parallel to outer margin, distal half of inner margin slightly concave (Fig. 12H); 8) dorsal margin of forefemur with one row of long spine-setae from base to apex (Fig. 13A); 9) forefemur on anterior surface with small spine-like setae at middle (Fig. 13A); 10) patella-tibial suture absent; 11) distal margin of terga with wide spines (Fig. 14A).

\section{Etymology}

'Uiara' is the Rivers Queen in Amazonian folklore a divinity that protects waters and kills men. Name in apposition.

\section{Material examined}

Holotype

BRAZIL • nymph on slide; Amazonas, Presidente Figueiredo, AM 240 Highway, Km 21, stream Recanto da Pantera; 0202'33.15"'S, 5950'56.13" W; 13 Dec. 2011; P.V. Cruz leg; sand; INPA.

\section{Paratypes}

BRAZIL • 5 nymphs; same collection data as for holotype; INPA.

\section{Description}

\section{Imago}

See description in Cruz et al. (2011).

\section{Nymph}

LeNGTH. Body, 3.3-3.5 mm.

HEAD. Antenna. Flagellum with minute spines on apex of each segment. Labrum (Fig. 12A). Rectangular, length about $0.6 \times$ maximum width; distal margin with small medial emargination, one row of robust, eventually pectinated, setae from lateral to middle of distal margin; one row of thin bifid setae on distal margin not reaching distolateral margin; dorsal surface, near distal margin, with many thin setae over surface. Left mandible (Fig. 12B). Incisors partially cleft in two sets (fused at basal third); outer and inner set of incisors respectively with $4+3$ denticles, outer incisor with a pectinated spine-like process; prostheca robust; margin between prostheca and mola straight; tuft of spine-like setae at base of mola absent; subtriangular process wide; denticles of mola not constricted; mola with two large denticles, 


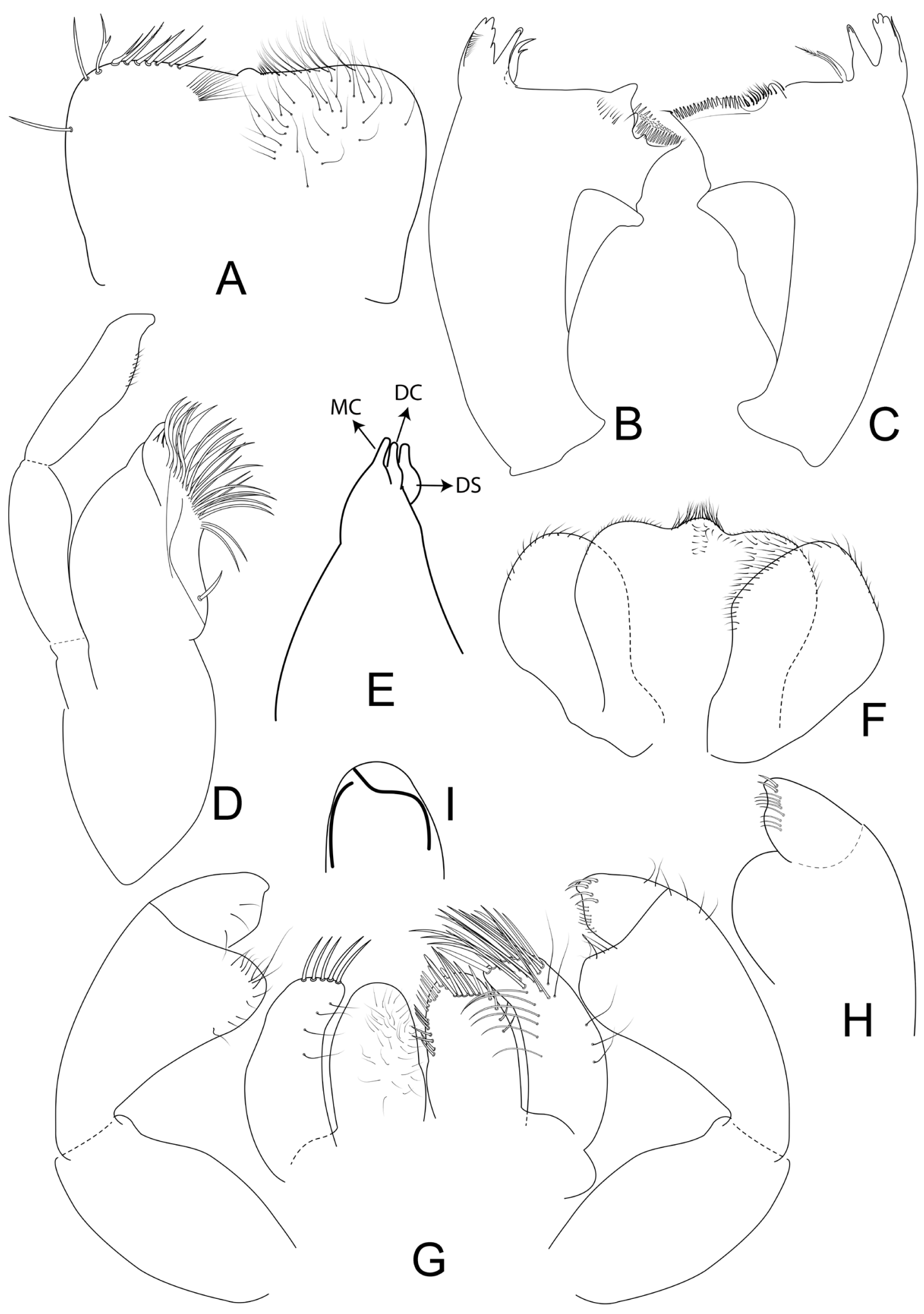

Fig. 12. Rivudiva uiara sp. nov., holotype (INPA). A. Labrum (left v.v., right d.v.). B. Left mandible. C. Right mandible. D. Maxilla. E. Apex of maxilla v.v. $(\mathrm{DS}=$ dentiseta, $\mathrm{DC}=$ dorsal canine, $\mathrm{MC}=$ medial canine). F. Hypopharynx. G. Labium (left v.v., right d.v.). H. Variation of apex of segment II and segment III of labial palp. I. Shape of distal rows of setae of glossa. Not to scale. 




Fig. 13. Rivudiva uiara sp. nov., holotype (INPA). A. Foreleg (femur on anterior surface). B. Detail of fore claw. C. Posterior surface of forefemur. D. Hind leg (femur on anterior surface). E. Posterior surface of hind femur. Not to scale. 

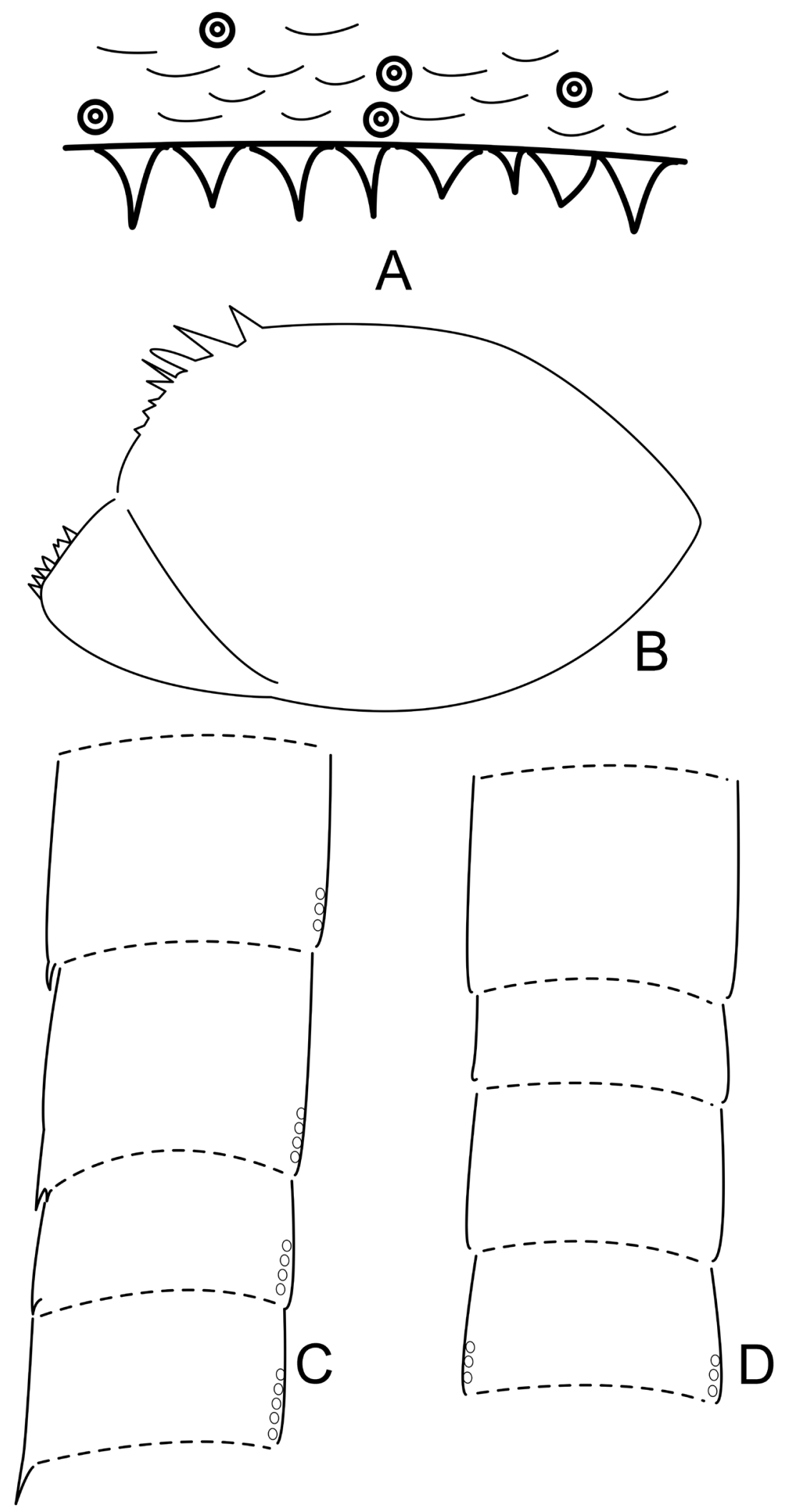

Fig. 14. Rivudiva uiara sp. nov., holotype (INPA). A. Margin of tergum IV. B. Paraproct. C. Cercus. D. Paracercus. Not to scale. 


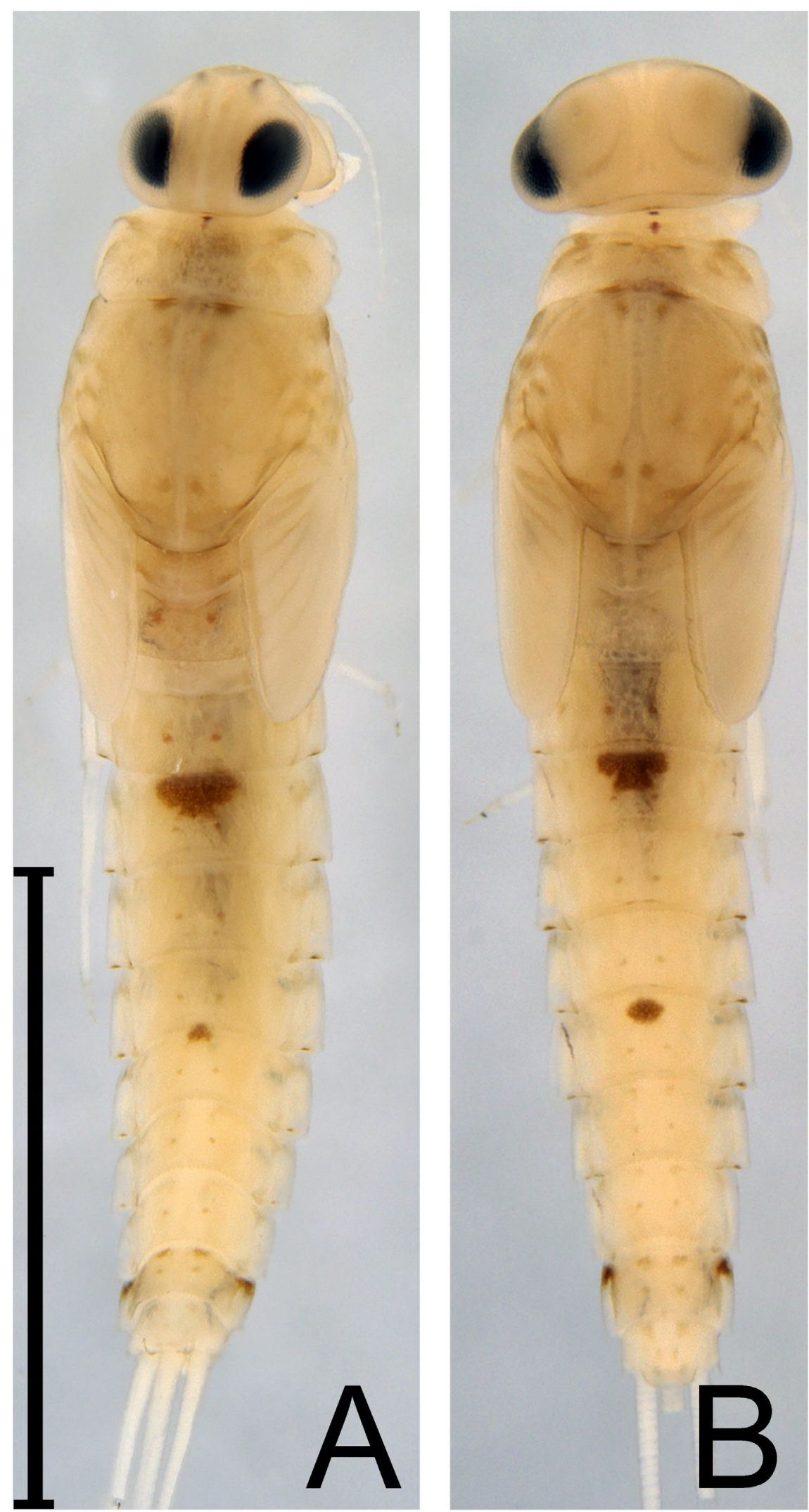

Fig. 15. Rivudiva uiara sp. nov. A. Dorsal habitus of female nymph, holotype (INPA). B. Dorsal habitus of male nymph, paratype (INPA). Scale bar $=1.65 \mathrm{~mm}$. 
inner larger than outer; outer margin convex. Right mandible (Fig. 12C). Incisors fused at base; outer and inner set of incisors respectively with $3+3$ denticles and outer incisor with spine-like process; prostheca stout, bifurcated at middle, inner lobe longer and pectinate; margin between prostheca and mola straight; tuft of spine-like setae at base of mola present; denticles of mola not constricted; apex of mola with one simple seta; first process of mola triangular, second expanded and straight; outer margin convex. Maxilla (Fig. 12D-E). Maxillary palp $1.6 \times$ length of galea-lacinia; segment II $1.1 \times$ length of segment I; segment II inner margin with small apical lobe; ventral canine enlarged, not laterally expanded; set of distal setae of inner-ventral row pointed. Hypopharynx (Fig. 12F). Lingua longer than superlingua, sub-quadrangular with small distomedial projection covered by tuft of simple setae, lateral area of distomedial projection excavated; superlingua with rounded outer margin; short, thin, simple setae scattered over distal margin of lingua and superlingua. Labium (Fig. 12G-I). Glossa slightly broad at base, distally rounded, shorter than paraglossa; inner margin with one row of spine-like setae starting at half length; ventral surface covered by thin setae; dorsal surface with inner arc with robust setae following inner-distal margin, outer arc at base following outer margin, at apex sinuous; one robust blunt seta on apex. Paraglossa curved inward; apex with two rows of robust and long spine-like setae; outer margin with three long thin setae; dorsal surface with three longitudinal rows of setae, first near inner margin longer than half of length, distally with long robust setae and basally with long thinner setae; second with half of length of inner row, with robust long setae; and third with same length as second, distal setae long and robust, basal setae long and thin; ventral surface with one row of four setae near to ventral margin. Labial palp with segment I $0.6 \times$ length of segments II and III combined; inner distal protuberance of segment II rounded, with almost straight distal margin, covered with thin setae; segment III conical, inner margin on basal half parallel to outer margin, distal half of inner margin slightly concave; outer margin with short thin setae, dorsal surface with one row of short spine-like setae near inner margin, ventral surface with one row of thin setae.

Thorax. Foreleg (Fig. 13A-C). Femur length about $3.7 \times$ maximum width; dorsal and ventral margin with one row of long spine-like setae; anterior surface with one medial row of short blunt setae, one row of long spine-like setae near dorsal margin not reaching apex; posterior surface with one row of long spine-like setae near ventral margin reaching apex, and one medial row of long spine-like setae. Tibia. Dorsally bare; ventral margin with one row of long spine-like setae; patella-tibial suture absent. Tarsus. Ventral margin with one row of spine-like setae. Tarsal claws $0.4 \times$ length of tarsus, with two rows of pointed denticles reaching apex. Hind leg (Fig. 13D-E). Femur dorsal and ventral margin with one row of long spine-like setae; anterior surface with one row of spine-like setae near dorsal margin, one row of long spine-like setae near ventral margin; posterior surface with one row of long spine-like setae near ventral margin reaching apex. Tibia. Dorsally bare; ventral margin with one row of small blunt setae; patella-tibial suture present. Tarsus. Ventral margin with one row of small blunt setae. Tarsal claws $0.5 \times$ length of tarsus, with two rows of pointed denticles reaching apex.

ABdomen. Terga (Fig. 15) with all segments white (color lost in alcohol), terga I-IX with two small medial red dots; tergum III with one large medial red mark near distal margin; tergum VI with one medial red mark near distal margin; terga VII and IX with two red marks near distal margin, tergum IX with brown mark on disto-lateral margin. Posterior margin of terga with small triangular spines (Fig. 14A). Gills missing. Paraproct (Fig. 14B) with eight to nine marginal spines, posterolateral extension with spines. Cerci (Fig. 14C) with lateral spines on every segment. Paracercus (Fig. 14D) without spines.

$$
\begin{aligned}
& \text { Rivudiva naia sp. nov. } \\
& \text { urn:1sid:zoobank.org:act:FC398BC7-7504-4F40-AF67-9479BABF0926 } \\
& \text { Figs 16-18 }
\end{aligned}
$$

\section{Diagnosis}

NyMPH. The combination of the characters: 1) labrum distal margin straight (Fig. 16A); 2) labrum ventral surface with simple or pectinated robust setae on distal margin (Fig. 16A); 3) left mandible with incisors fused at basal third (Fig. 16B); 4) maxillary palp segment II with large apical lobe (Fig. 16D); 
5) superlingua with truncate outer margin (Fig. 16F); 6) outer arc of robust setae of glossa close to margin, slightly removed from distal margin (Fig. 16G); 7) labial palp segment III conical, apex broad pointed (Fig. 16G); 8) dorsal and ventral margin of forefemur with one row of long spine-setae from base to apex (Fig. 17A); 9) forefemur on anterior surface with short blunt setae at middle (Fig. 17A); 10) patella-tibial suture present; 11) distal margin of terga with wide spines (18A).

\section{Etymology}

'Naia' in Amazonian folklore is the name of the native woman that, after being drowned by the enchantment of the god Moon, was transformed into a water star - Victoria Regia (Victoria amazonica (Poepp.) J.C.Sowerby). For this reason, the fragrant whitish flowers of this plant only open at night. Name in apposition.

\section{Material examined}

\section{Holotype}

BRAZIL - nymph on slide; Roraima, Mucajaí, Apiaú, waterfall Esmeralda; 02 $29^{\prime} 42.76^{\prime \prime} \mathrm{N}$, 612'ㄴ'41.61" W; 14 Feb. 2021; R. Boldrini leg.; sand; UFRR.

\section{Paratypes}

BRAZIL 1 nymph; same collection data as for holotype; UFRR 1 nymph; same collection data as for holotype; UFV $\bullet 1$ nymph; same collection data as for holotype; INPA.

\section{Description \\ Nymph \\ LeNGTH. Body, 4.1-4.9 mm.}

HEAD. Antenna. Flagellum with minute spines on apex of each segment. Labrum (Fig. 16A). Rectangular, length about $0.6 \times$ maximum width; distal margin straight, one row of robust, eventually pectinated, setae from lateral to middle of distal margin; one row of thin bifid setae on distal margin not reaching distolateral margin; dorsal surface, near distal margin, with many thin setae over surface. Left mandible (Fig. 16B). Incisors partially cleft in two sets (fused at basal third); outer and inner set of incisors respectively with $4+3$ denticles; prostheca robust; margin between prostheca and mola straight; tuft of spine-like setae at base of mola absent; subtriangular process wide; denticles of mola not constricted; mola with two large denticles, inner larger than outer; outer margin convex. Right mandible (Fig. 16C). Incisors fused at base; outer and inner set of incisors respectively with $3+2$ denticles and outer incisor with spine-like process; prostheca stout, bifurcated at base, inner lobe longer than outer; margin between prostheca and mola straight; tuft of spine-like setae at base of mola present; denticles of mola not constricted; apex of mola with one simple seta; first process of mola triangular, second expanded and straight; outer margin convex. Maxilla (Figs 16D). Maxillary palp $1.8 \times$ length of galea-lacinia; segment II $1.2 \times$ length of segment I; segment II inner margin with large apical lobe; ventral canine enlarged, not laterally expanded; set of distal setae of the inner-ventral row pointed. Hypopharynx (Fig. 16E). Lingua longer than superlingua, sub-quadrangular with a small distomedial projection covered by tuft of simple setae; superlingua with truncate outer margin; short, thin, simple setae scattered over distal margin of lingua and superlingua. Labium (Fig. 16F-G). Glossa slightly expanded at base, distally rounded, shorter than paraglossa; ventral surface covered by thin setae; dorsal surface with inner arc with setae following inner-distal margin, outer arc at base following outer margin, slightly far from distal margin. Paraglossa curved inward; apex with one row of robust and long spine-like setae; outer margin with four long thin setae; dorsal surface with four longitudinal rows of setae, first near inner margin longer than two third of length, distally with long robust setae and basally with long thinner setae; second with third of length of inner row, with robust long setae; and third with same length as second, distal setae long and robust, basal setae long and thin; 


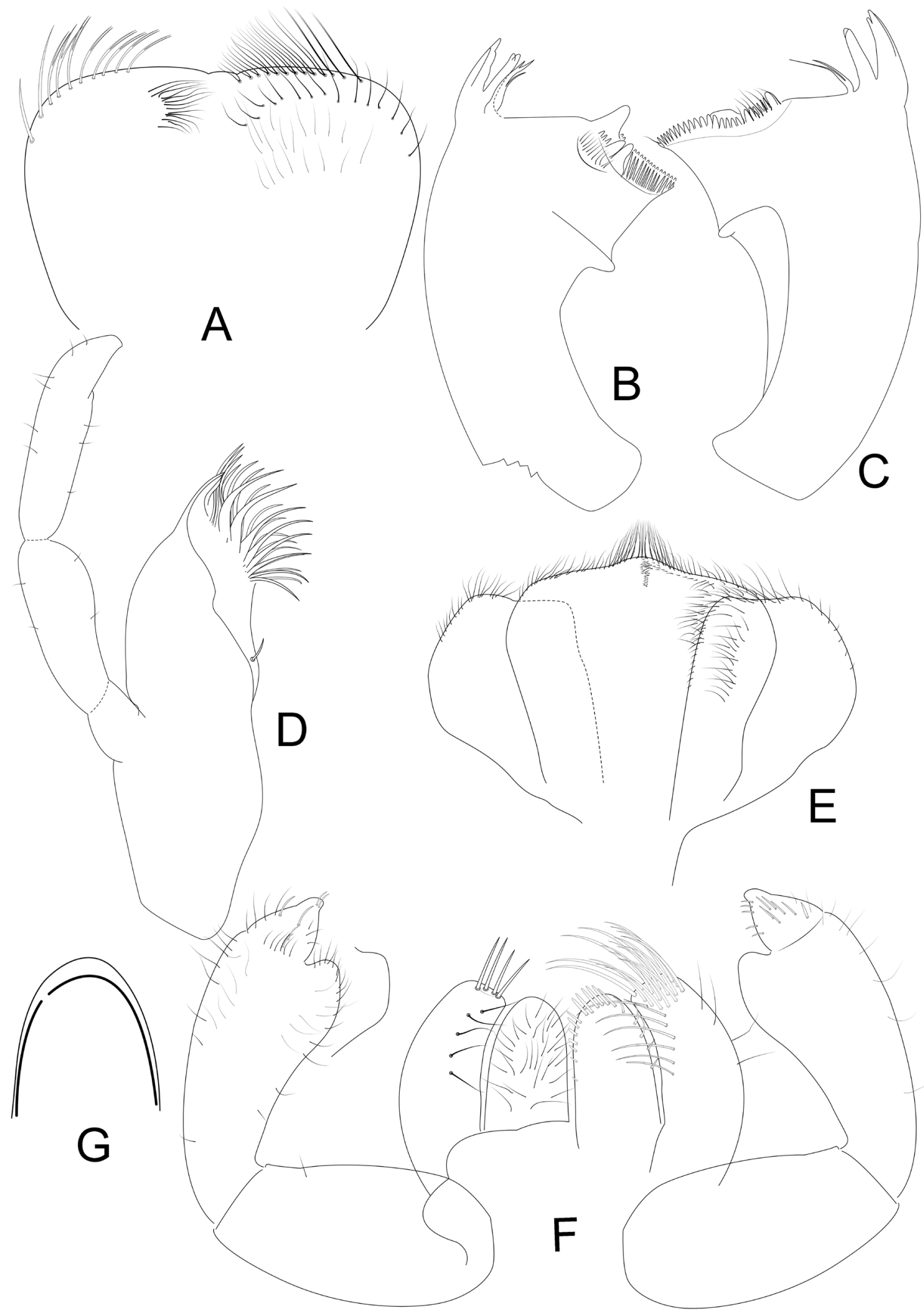

Fig. 16. Rivudiva naia sp. nov., holotype (UFRR). A. Labrum (left v.v., right d.v.). B. Left mandible. C. Right mandible. D. Maxilla. E. Hypopharynx. F. Labium (left v.v., right d.v.). G. Shape of distal rows of setae of glossa. Not to scale. 


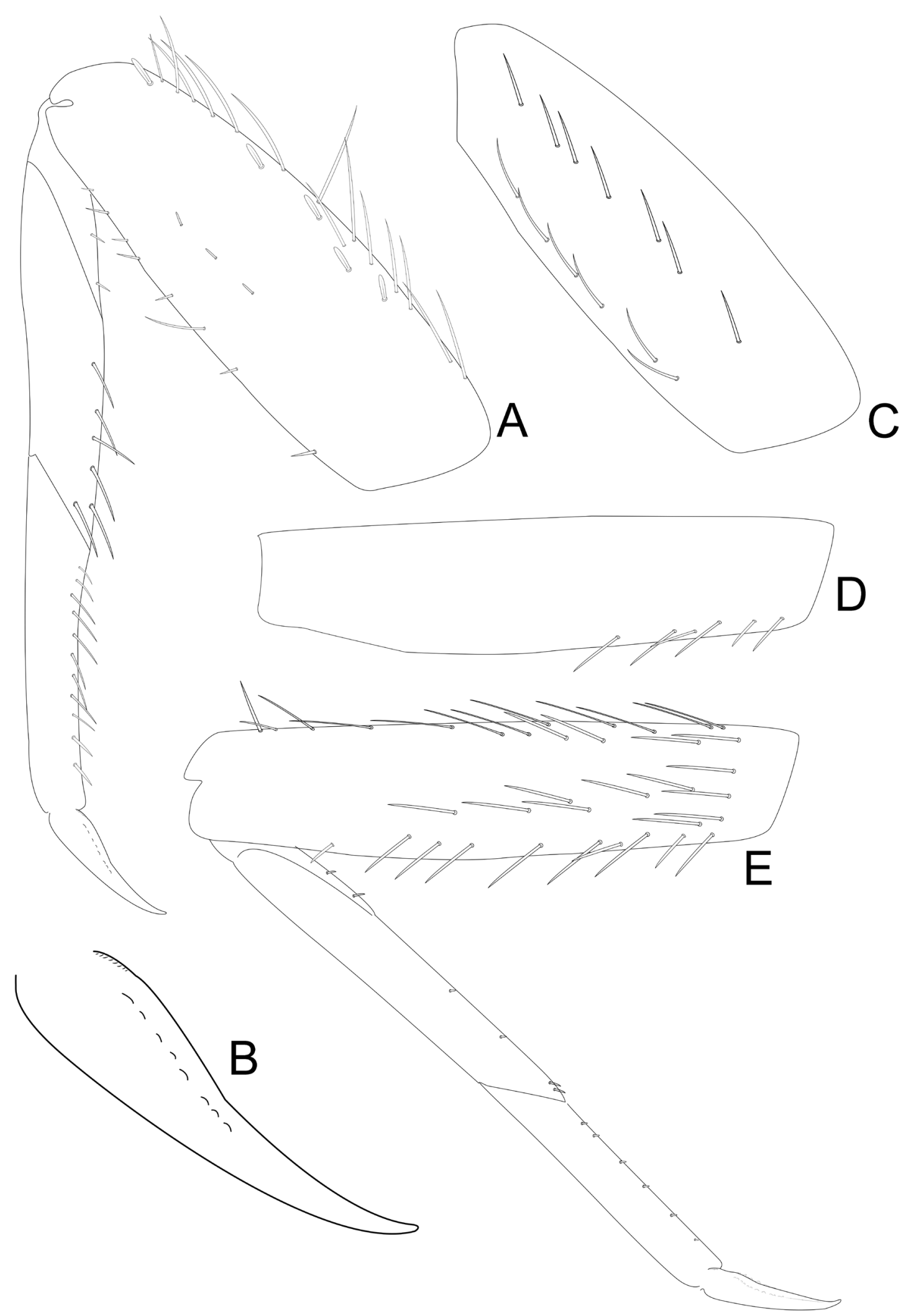

Fig. 17. Rivudiva naia sp. nov., holotype (UFRR). A. Foreleg (femur on anterior surface). B. Detail of fore claw. C. Posterior surface of forefemur. D. Posterior surface of hind femur. E. Hind leg (femur in anterior surface). Not to scale. 


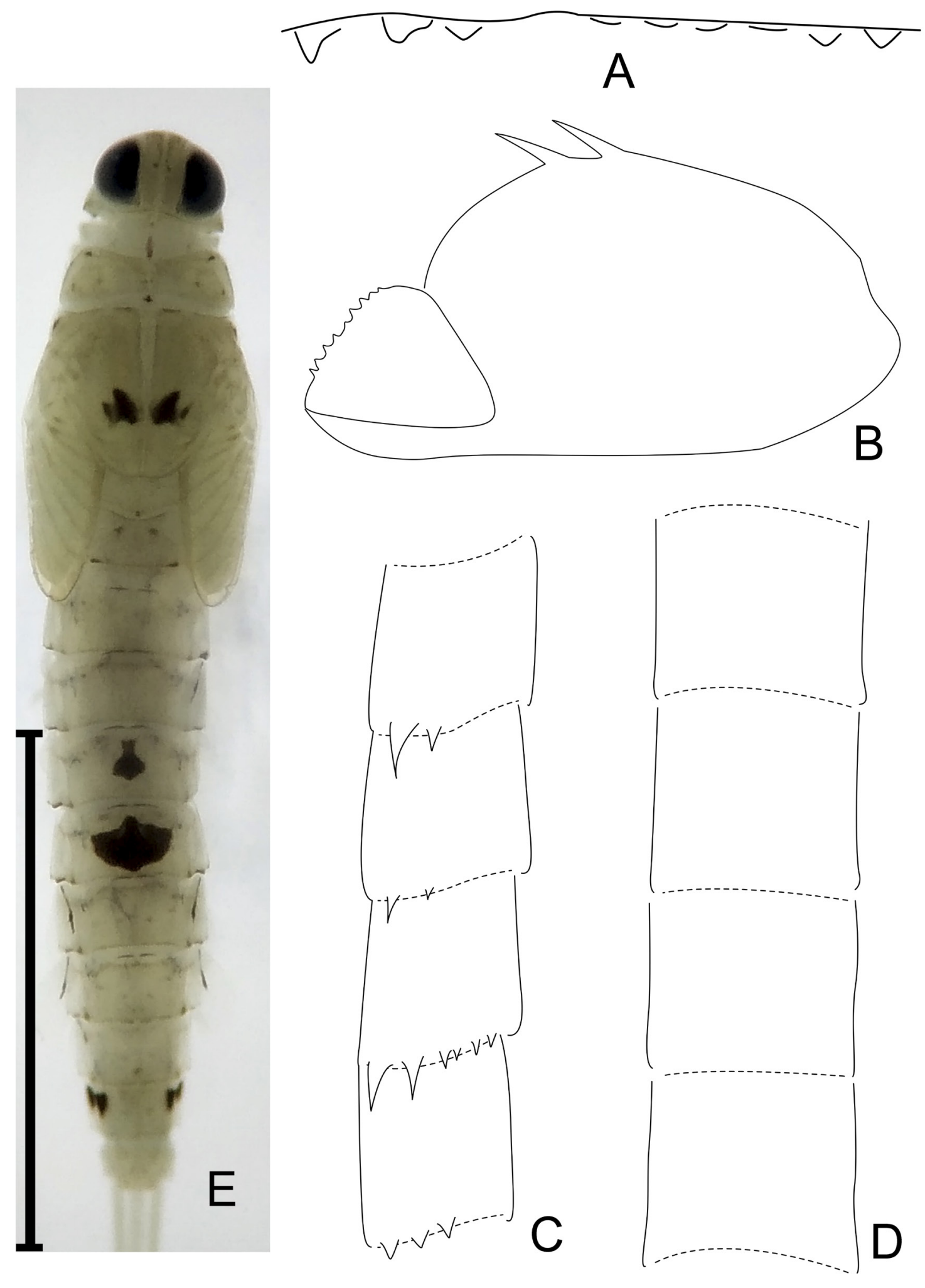

Fig. 18. Rivudiva naia sp. nov., holotype (UFRR). A. Margin of tergum IV. B. Paraproct. C. Cercus. D. Paracercus. E. Dorsal habitus of female nymph. Scale bar: E $=2.0 \mathrm{~mm}$; A-D not to scale. 
ventral surface with one row of five setae near to ventral margin. Labial palp with segment I $0.8 \times$ length of segments II and III combined; inner distal protuberance of segment II rounded and projected to apex, covered with thin setae; segment III conical, apex broad pointed; outer margin with short thin setae, dorsal surface with one row of short spine-like setae near inner margin, ventral surface with one row of thin setae.

THORAX. One mark on mesothorax. Foreleg (Fig. 17A-C). Femur length about $2.9 \times$ maximum width; dorsal and ventral margin with one row of long spine-like setae; anterior surface with one medial row of short setae, one row of blunt setae near dorsal margin not reaching apex; posterior surface with one row of long spine-like setae near ventral margin reaching apex, and one medial row of long spine-like setae. Tibia. Dorsally bare; ventral margin with one row of long spine-like setae; patella-tibial suture present. Tarsus. Ventral margin with one row of spine-like setae. Tarsal claws $0.4 \times$ length of tarsus, with two rows of rounded denticles at basal half. Hind leg (Fig. 17D-E). Femur dorsal and ventral margin with one row of long spine-like setae; anterior surface with one row of spine-like setae near dorsal margin, one row of long spine-like setae near ventral margin; posterior surface with one row of spine-like setae near ventral margin at basal half. Tibia. Dorsally bare; ventral margin with one row of small spine-like setae; patella-tibial suture present. Tarsus. Ventral margin with one row of small spine-like setae. Tarsal claws $0.5 \times$ length of tarsus, with two rows of rounded and small denticles reaching apex.

ABDOMEn. Terga (Fig. 18E) with all segments white (color lost in alcohol), tergum IV with one medialred mark; tergum V with one large medial red mark; tergum IX with one red mark near lateral margin. Posterior margin of terga with small triangular blunt spines (Fig. 18A). Gills oblong, longer than next segment, with one medial trachea red pigmented. Paraproct (Fig. 18B) with two marginal spines, posterolateral extension with spines. Cerci (Fig. 18C) with lateral spines on every segment. Paracercus (Fig. 18D) without spines.

\section{Rivudiva sp. X}

Rivudiva trichobasis - Boldrini et al. 2012: 93. - Salles et al. 2020: 49.

\section{Diagnosis}

Nyмpн. 1) labrum distal margin straight; 2) apex of segment II of maxillary palp with strong inner projection.

\section{Material examined}

BRAZIL $\cdot 2$ nymphs (one on slide and other without head); Maranhão, River Farinha, BR-010, near the bridge; 06² 3'47.3" S, 47²8'11.4" W; 22 Jul. 2010; R. Boldrini, P.V. Cruz and Hamada N. leg.; UFRR.

\section{Comments}

In Boldrini et al. (2012), this unidentifiable specimen was named as $R$. trichobasis. The specimens studied are in bad condition, with essential structures broken and missing, such as head, labium, hypopharynx, part of maxilla and abdomen. However, based on the maxillary palp, it is probably a new species.

Species not assigned to trichobasis group

Rivudiva coveloae (Traver, 1971)

Fig. 19

Baetis coveloae Traver, 1971: 61.

Camelobaetidius coveloae - Lugo-Ortiz \& McCafferty 1999: 258. — Domínguez et al. 2006: 129.

Rivudiva coveloae - Salles \& Nascimento 2009: 234. — Salles et al. 2020: 42. 


\section{Diagnosis}

MALE IMAGO. 1) dorsal portion of turbinate eyes with inner margins parallel, and oval (Fig. 19A); 2) hind wings present (Fig. 19D); 3) anterior margin of abdominal terga darker (Fig. 19A); 4) unistyliger cylindrical with small inner projection (Fig. 19C); 5) first segment of gonostylus elongated, length more than half of second segment, third segment elongate (Fig. 19C, E); 6) styliger plate concave, with one medial spine (Fig. 19F-G); 7) gonovectis short, sinuous, not deep into segment IX (Fig. 19E-F).

\section{Material examined}

\section{Holotype}

URUGUAY • ○’; Prov. Maldonado, Cerro Animas; 14 Sep. 1950; C.S. Carbonell leg.; PERC.
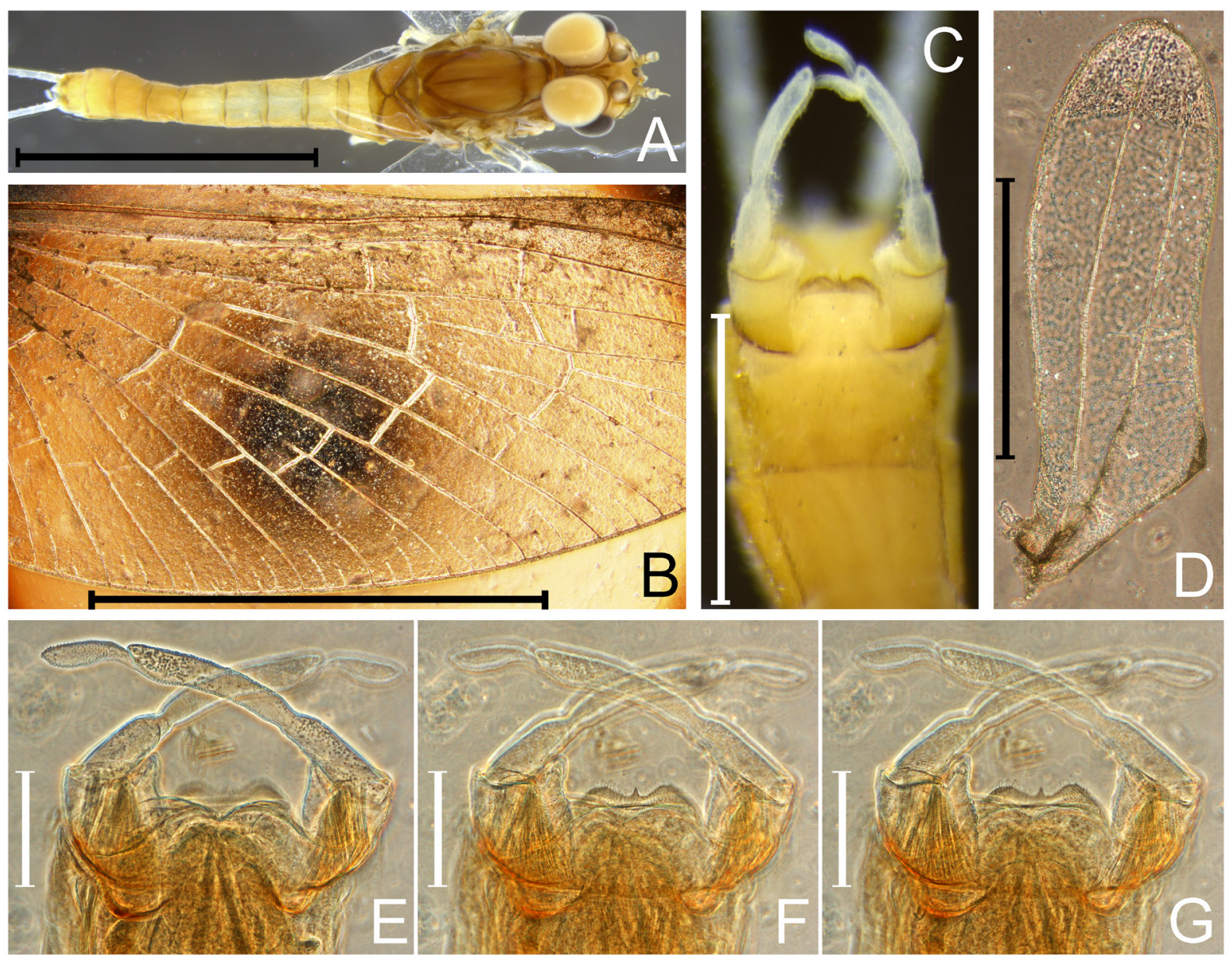

Fig. 19. Rivudiva coveloae (Traver, 1971) male imago, holotype (PERC). A. Dorsal view. B. Detail of forewing. C. Genitalia (v.v.). D. Hind wing. E. Detail of genitalia (d.v.). F. Detail of genitalia (v.v.). G. Detail of genitalia (v.v.). Scale bars: A-B $=2.5 \mathrm{~mm} ; \mathrm{C}=0.3 \mathrm{~mm} ; \mathrm{D}=0.45 \mathrm{~mm} ; \mathrm{E}-\mathrm{G}=0.08 \mathrm{~mm}$. 


\section{Rivudiva venezuelensis (Traver, 1943)}

Fig. 20

Pseudocloeon venezuelensis Traver, 1943: 92.

Cloeodes venezuelensis - Lugo-Ortiz \& McCafferty 1999: 261. — Domínguez et al. 2006: 153. Rivudiva venezuelensis - Salles \& Nascimento 2009: 234. — Salles et al. 2020: 43.
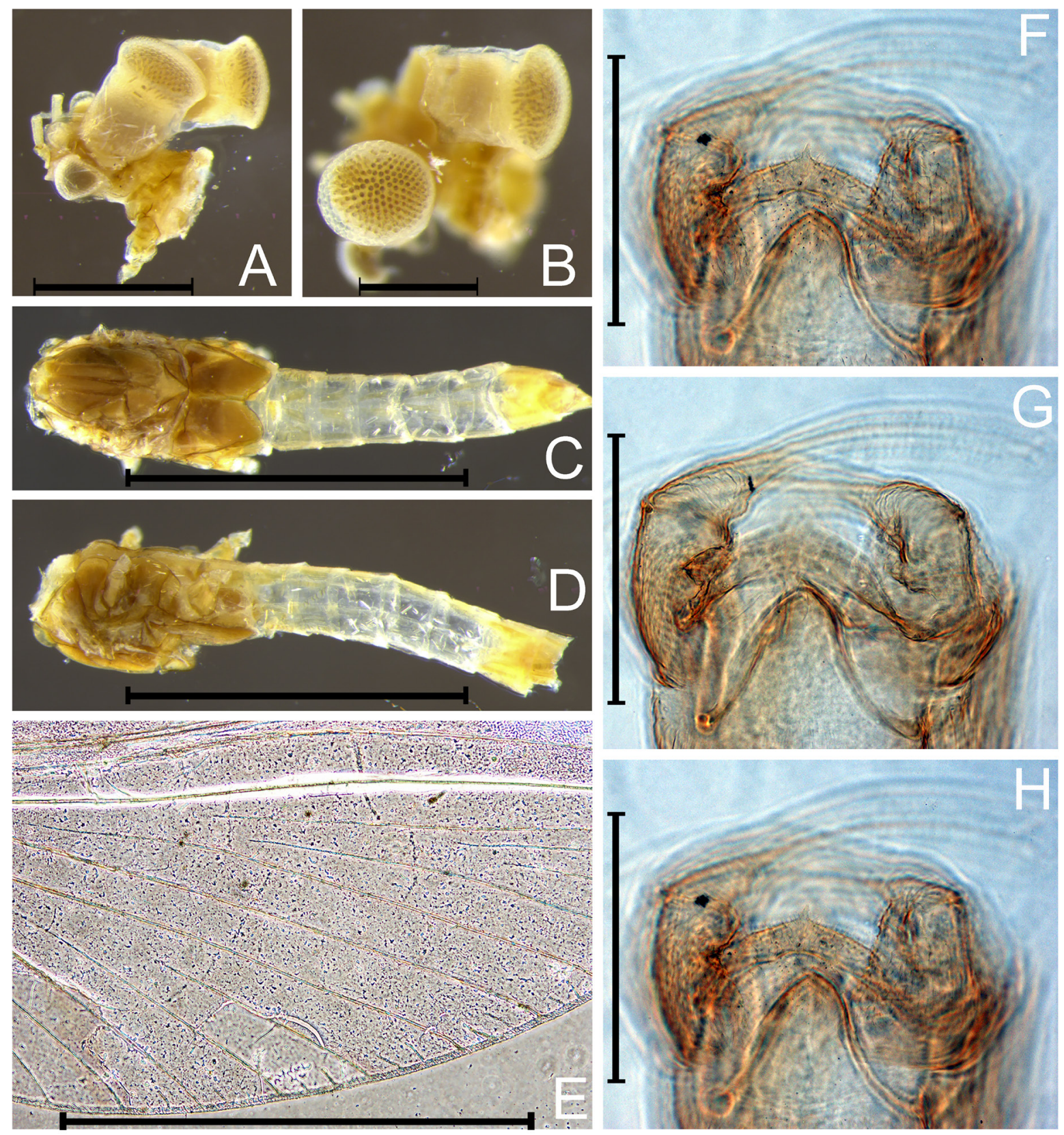

Fig. 20. Rivudiva venezuelensis (Traver, 1943) male imago, holotype (PERC). A. Head (1.v.). B. Head (d.v.). C. Body (d.v.). D. Body (l.v.). E. Detail of forewing. F. Detail of genitalia (v.v.). G. Detail of genitalia (d.v.). H. Detail of genitalia (v.v.). Scale bars: $A=0.44 \mathrm{~mm} ; B=0.23 \mathrm{~mm}$; $-\mathrm{D}=1.3 \mathrm{~mm}$; $E=$ $1.25 \mathrm{~mm} ; \mathrm{F}-\mathrm{H}=0.13 \mathrm{~mm}$. 


\section{Diagnosis}

MALE IMAGO. 1) dorsal portion of turbinate eyes with inner margins parallel, and circular (Fig. 20A-B); 2) hind wings absent; 3) abdominal segments I-VI translucid (Fig. 20C-D); 4) unistyliger cylindrical (Fig. 20F-H); 5) first segment of gonostylus short, length less than half of second segment, third segment clavate (Fig. 20F-H); 6) styliger plate convex, with one medial spine (Fig. 20F-H); 7) gonovectis long, V-like, deep into segment IX (Fig. 20F-H).

\section{Material examined}

Holotype

VENEZUELA • ○’; Antimano; 900 m a.s.1., 13 Jan. 1940; R. Lichy leg.; PERC.

\section{Discussion}

Study of the paratype and four of the six official records of $R$. trichobasis (Lugo-Ortiz \& McCafferty 1998; Cruz et al. 2011; Falcão et al. 2011; Boldrini et al. 2012; Boldrini \& Cruz 2014), under the new perspective (Cruz et al. 2018; Salles et al. 2020), corroborated the initial hypothesis that the lack of information resulted in a broad diagnosis of the species, causing the assignment of different species to a single name.

The change in species concept, from a single species with a wide distribution and morphological plasticity to a group of closely related species, is well grounded in morphology. The evidence here presented demonstrates clearly that ' $R$. trichobasis Lugo-Ortiz \& McCafferty, 1998' is, in fact, a complex of species. In parallel to morphology, a molecular approach would have strengthened the status and validity of the different species. We hope that this approach will be possible in the near future.

The change in species concept does not interfere with the inclusion of the genus in the subfamily Baetinae (sensu Cruz et al. 2021) [= Baetovectata Kluge \& Novikova 2011], and in the generic delimitation proposed by Cruz et al. (2018) and Salles et al. (2020). However, amendments need to be made. All species present ventral canine of the maxilla expanded, laterally folded over canines only in $R$. inma Salles \& Nieto in Salles et al., 2020 and R. trichobasis. In all species the distal dentiseta is canine-like, while the other dentisetae are seta-like; and the distal setae on the inner-ventral row of the maxilla bend over the canines.

From a subgeneric perspective, Salles et al. (2020) hypothesized that there are two morphological groups of species in Rivudiva ( $R$. minantenna Lugo-Ortiz \& McCafferty $1998+R$. inma and $R$. trichobasis + $R$. oonirikoperi Cruz, 2020 in Salles et al. 2020). Our results corroborate the existence of two distinct morphological groups (minantenna and trichobasis) plus $R$. oonirikoperi.

The trichobasis group is mainly characterized by spine-like setae on the scape and pedicel. This group could be related to $R$. oonirikoperi based on the presence of spine-like processes on the outer margins of the mandibular incisors (Salles et al. 2020: figs 12-13), glossa not expanded at base and apically rounded (Salles et al. 2020: fig. 16), hindwing pads absent, and the presence of robust apically pointed setae on abdominal sterna (Salles et al. 2020: figs 36-37). Additionally, R. oonirikoperi and the trichobasis group also share arcs of setae on glossa close to inner and outer margins, and groups of setae on the legs. The minantenna group ( $R$. minantenna $+R$. inma) is characterized by glossa with base expanded and apex obliquely truncate (Salles et al. 2020: fig. 6), hind wing pads present, and abdominal sterna with simple setae (Salles et al. 2020). Additionally, both species share outer arc of setae on glossa moved to inner margin. The hypothesis of groups has not yet been tested, Cruz et al. $(2018,2021)$ included $R$. minantenna and $R$. trichobasis in the cladistic analyses, the two species known by their nymphal stage at that time. 
Within the trichobasis group, $R$. trichobasis can be quickly differentiated from other species by the maxillary ventral canine expanded, laterally folded over the canines (Fig. 1E). Rivudiva amazona sp. nov. and $R$. naia sp. nov. can be quickly differentiated from $R$. oxum sp. nov. and $R$. uiara sp. nov. by outer arc of setae on glossae not sinuous in the first two species (Figs 4H, 16G), and sinuous in the last two species (Figs 8K, 12I). Rivudiva amazona sp. nov. can be quickly differentiated from $R$. naia sp. nov. by segment III of labial palp apically pointed (Fig. 4G) vs broadly pointed in $R$. naia sp. nov. (Fig. 16F) and paraproct with nine to eleven marginal spines (Fig. 6B) vs with two in R. naia sp. nov. (Fig. 18B). Rivudiva oxum sp. nov. can be quickly differentiated from $R$. uiara sp. nov. by maxillary palp segment II with long distal lobe (Fig. 8D) vs with small in R. uiara sp. nov. (Fig. 12D), segment III of labial palp apically pointed (Fig. 8J) vs rounded with concavity in $R$. uiara sp. nov. (Fig. 12G).

In addition to the differences in morphology, the species seem to have allopatric distributions (Fig. 21); therefore, at this point, distribution is probably a useful character for separating them. Rivudiva trichobasis seems to be restricted to the Pampa Biome; $R$. amazona sp. nov. seems to be restricted to the Amazon in southern Roraima; $R$. naia sp. nov. seems to be restricted to the ecotone between the Amazon forest and the Roraima savanna; $R$. oxum sp. nov. seems to be present in savanna areas in the Southwestern Amazon; R. uiara sp. nov. seems to be restricted to the Central Amazon; Rivudiva sp. X was collected in the ecotone between the Amazon and Cerrado Biomes.

Considering that all previous Amazonian and Cerrado reports are new species, the records from the Atlantic Forest Biome (Espírito Santo State) (Salles et al. 2020) and from Paraguay (Lugo-Ortiz \& McCafferty 1998) are treated as putative and must be reevaluated considering the new evidence.



Fig. 21. Map of Brazil showing the distribution of the distinct species of 'trichobasis group' and Brazilian biomes. 
Salles et al. (2020), based on geographic distribution, discussed the possibility of $R$. oonirikoperi being, in fact, the nymphal stage of Rivudiva venezuelensis (Traver, 1943). However, in $R$. venezuelensis characteristics such as turbinate eyes circular, body pigmentation pattern without typical marks on segments II, III and VI, and gonovectis V-like, deep in segment IX, are similar to Paracloeodes, and not to Rivudiva. Using the proximity criteria, $R$. minantenna could also be the nymphal stage of $R$. coveloae (Traver, 1971). Rivudiva coveloae is likely to belong to Rivudiva due to its having hind wings, oval turbinate eyes and sinuous gonovectis not deep in segment IX; on the other hand, the pigmentation patterns of the abdomen are not the typical marks on segments II, III and VI. It is not possible to resolve these doubts based on the evidence presented here.

In conclusion, there were six species under the name 'trichobasis', five of them properly redescribed or described here. We recommend the evaluation of unreviewed records using the new morphological evidence presented herein, as well molecular studies.

\section{Acknowledgments}

This study was financed by the following projects: Sistemática integrada de insetos aquáticos, com ênfase em Simuliidae (Diptera) na América do Sul (MCTIC/INPA), Biodiversidade de Ephemeroptera do Estado de Rondônia (MEC/UNIR); CAPES/Pro-equipamentos-DCEN; Insetos Aquáticos na América do Sul: taxonomia integrativa, biologia e ecologia, CNPq process n. 308970/2019-5 and FAPEAM/ Programa POSGRAD-2019. P.V.C. is grateful for the support from the Fundación-Instituto Miguel Lillo by Carolina Nieto and from the Purdue Entomological Research Collection (PERC) by Luke Jacobus. A grant from Ernst Mayr Travel Grants in Animal Systematics at the Museum of Comparative Zoology, Harvard University, allowed us to study the types deposited in the PERC. We are grateful to Dr JeanLuc Gattolliat and Dr Helen M. Barber-James for critical comments on the manuscript; and to Dr Philip M. Fearnside for a language review.

\section{References}

Boldrini R. \& Cruz P.V. 2014. Baetidae (Insecta: Ephemeroptera) from the state of Rondônia, Northern Brazil. Boletim do Museu Integrado de Roraima 8: 1-9. https://doi.org/10.24979/bolmirr.v8i01.763

Boldrini R., Cruz P.V., Salles F.F., Belmont E.L. \& Hamada N. 2012. Baetidae (Insecta: Ephemeroptera) from northeastern Brazil. Check List 8 (1): 88-94. https://doi.org/10.15560/8.1.088

Coleman C.O. 2006. Substituting time-consuming pencil drawings in arthropod taxonomy using stacks of digital photographs. Zootaxa 1360 (1): 61-68. https://doi.org/10.11646/zootaxa.1360.1.4

Cruz P.V. 2020. Redescription of three species of Apobaetis Day, 1955 (Ephemeroptera: Baetidae). Zootaxa 4808 (2): 317-330. https://doi.org/10.11646/zootaxa.4808.2.5

Cruz P.V., Boldrini R., Salles F.F. \& Hamada N. 2011. The male imago of Rivudiva trichobasis LugoOrtiz \& McCafferty from Amazonas state, Brazil. Zootaxa 2907: 60-62.

Cruz P.V., Salles F.F. \& Hamada N. 2018. A cladistic approach for generic delimitation of Paracloeodes Day, Rivudiva Lugo-Ortiz \& McCafferty, and Varipes Lugo-Ortiz \& McCafferty (Ephemeroptera: Baetidae). Insect Systematic \& Evolution 1: 1-20.

Cruz P.V., Salles F.F., Hamada N. \& Falcão J.N. 2020. New genus and species of Baetidae (Insecta: Ephemeroptera) from Brazil. Zootaxa 4729 (1): 127-137. https://doi.org/10.11646/zootaxa.4729.1.9

Cruz P.V., Nieto C., Gattolliat J.-L., Salles F.F. \& Hamada N. 2021. A cladistic insight into the higher level classification of Baetidae (Insecta: Ephemeroptera). Systematic Entomology 46: 44-55.

https://doi.org/10.1111/syen.12446 
Domínguez E., Molineri C., Pescador M.L., Hubbard M.D. \& Nieto C. 2006. Ephemeroptera of South America. In: Adis J., Arias J.R., Rueda-Delgado G. \& Wantzen K.M. (eds) Aquatic Biodiversity of Latin America. Volume 2: 1-646. Pensoft, Moscow-Sofia.

Falcão J.N., Salles F.F. \& Hamada N. 2011. Baetidae (Insecta, Ephemeroptera) ocorrentes em Roraima, Brasil: novos registros e chaves para gêneros e espécies no estágio ninfal. Revista Brasileira de Entomologia 55: 516-548. https://doi.org/10.1590/s0085-56262011005000048

Glazaczow A. 1997. Observations on the psammophilous mayfly species Procloeon nanum in the north east of Poland. In: Landolt P. \& Sartori M. (eds) Ephemeroptera \& Plecoptera. Biology EcologySystematics: 83-87. Mauron + Tinguely \& Lachat, SA., Fribourg.

Gutiérrez Y., Dias L.G. \& Salles F.F. 2013. Paracloeodes caldensis (Ephemeroptera: Baetidae), an atypical new species from the Colombian Andes. Zootaxa 3721: 291-295.

https://doi.org/10.11646/zootaxa.3721.3.6

Hubbard M.D. 1995. Toward a standard methodology for the description of mayflies (Ephemeroptera). In: Corkum L.D. \& Ciborowski J.J.H. (eds) Current Directions in Research on Ephemeroptera: 361-369. Canadian Scholars' Press, Inc., Toronto, Ontario.

Jacobus L.M. 2013. South Carolina mayflies (Insecta: Ephemeroptera) of conservation concern. Journal of the South Carolina Academy of Science 11: 21-26.

Lillie R.A. 1995. A survey of rare and endangered mayflies of selected rivers of Wisconsin. Wisconsin Department of Natural Resources Research Report 170: 23.

Lima L.R.C., Cruz P.V. \& Pinheiro U.S. 2013. The adult stages of Paracloeodes charrua Emmerich \& Nieto, 2009 (Ephemeroptera: Baetidae). Zootaxa 3640 (4): 597-600. https://doi.org/10.11646/zootaxa.3640.4.8

Lugo-Ortiz C.R. \& McCafferty W.P. 1998. Five new genera of Baetidae (Insecta: Ephemeroptera) from South America. Annales de Limnologie-International Journal of Limnology 34 (1): 57-73.

https://doi.org/10.1051/limn/1998007

Lugo-Ortiz C.R. \& McCafferty W.P. 1999. Revision of South American species of Baetidae (Ephemeroptera) previously placed in Baetis Leach and Pseudocloeon Klapalek. Annales de Limnologie-International Journal of Limnology 35 (4): 257-262. https://doi.org/10.1051/limn/1999034

McCafferty W.P. 1991. Comparison of Old and New World Acanthametropus (Ephemeroptera: Acanthametropodidiae) and other psammophilous mayflies. Entomological News 102: 205-214.

Orth K., Thomas A., Dauta C., Horeau V., Brosse S. \& Ademmer C. 2000. Les Ephémères de la Guyane française. 1. Premier inventaire générique, à but de biosurveillance (Ephemeroptera). Ephemera 2: 25-38.

Salles F.F. \& Nascimento J.M.C. 2009. The genus Rivudiva Lugo-Ortiz and McCafferty (Ephemeroptera: Baetidae): First generic description of adults, new combinations, and notes on the nymphs. Annales de Limnologie-International Journal of Limnology 45 (4): 231-235. https://doi.org/10.1051/limn/2009023

Salles F.F., Da-Silva E.R., Serrão J.E. \& Francischetti C.N. 2004. Baetidae (Ephemeroptera) na região sudeste do Brasil: novos registros e chave para os gêneros no estágio ninfal. Neotropical Entomology 33: 725-735. https://doi.org/10.1590/S1519-566X2004000600010

Salles F.F., Nieto C. \& Cruz P.V. 2020. New species of Rivudiva Lugo-Ortiz \& McCafferty (Ephemeroptera: Baetidae) with comments on $R$. minantenna Lugo-Ortiz \& McCafferty and $R$. trichobasis Lugo-Ortiz \& McCafferty. Zootaxa 4786 (1): 37-52. https://doi.org/10.11646/zootaxa.4786.1.3

Traver JR. 1943. New Venezuelan mayflies. Boletin de Entomologia Venezolana 2: 79-98.

Traver JR. 1971. Four new species of Neotropical Baetis (Ephemeroptera: Baetidae). Proceedings of the Entomological Society of Washington 73: 58-63. 
Manuscript received: 27 July 2021

Manuscript accepted: 15 November 2021

Published on: 3 February 2022

Topic editor: Nesrine Akkari

Section editor: Helen M. Barber-James

Desk editor: Radka Rosenbaumová

Printed versions of all papers are also deposited in the libraries of the institutes that are members of the EJT consortium: Muséum national d'histoire naturelle, Paris, France; Meise Botanic Garden, Belgium; Royal Museum for Central Africa, Tervuren, Belgium; Royal Belgian Institute of Natural Sciences, Brussels, Belgium; Natural History Museum of Denmark, Copenhagen, Denmark; Naturalis Biodiversity Center, Leiden, the Netherlands; Museo Nacional de Ciencias Naturales-CSIC, Madrid, Spain; Real Jardín Botánico de Madrid CSIC, Spain; Zoological Research Museum Alexander Koenig, Bonn, Germany; National Museum, Prague, Czech Republic. 